\title{
Black carbon ageing in the Canadian Centre for Climate modelling and analysis atmospheric general circulation model
}

\author{
B. Croft ${ }^{1}$, U. Lohmann ${ }^{2}$, and K. von Salzen ${ }^{3}$ \\ ${ }^{1}$ Department of Physics and Atmospheric Science, Dalhousie University, Halifax, Canada \\ ${ }^{2}$ Institute of Atmospheric and Climate Science, ETH Zurich, Zurich, Switzerland \\ ${ }^{3}$ Canadian Centre for Climate modelling and analysis, Meteorological Service of Canada, Victoria, Canada
}

Received: 1 March 2005 - Published in Atmos. Chem. Phys. Discuss.: 10 March 2005

Revised: 30 June 2005 - Accepted: 30 June 2005 - Published: 28 July 2005

\begin{abstract}
Black carbon (BC) particles in the atmosphere have important impacts on climate. The amount of $\mathrm{BC}$ in the atmosphere must be carefully quantified to allow evaluation of the climate effects of this type of aerosol. In this study, we present the treatment of $\mathrm{BC}$ aerosol in the developmental version of the 4th generation Canadian Centre for Climate modelling and analysis (CCCma) atmospheric general circulation model (AGCM). The focus of this work is on the conversion of insoluble BC to soluble/mixed BC by physical and chemical ageing. Physical processes include the condensation of sulphuric and nitric acid onto the $\mathrm{BC}$ aerosol, and coagulation with more soluble aerosols such as sulphates and nitrates. Chemical processes that may age the $\mathrm{BC}$ aerosol include the oxidation of organic coatings by ozone.
\end{abstract}

Four separate parameterizations of the ageing process are compared to a control simulation that assumes no ageing occurs. These simulations use 1) an exponential decay with a fixed $24 \mathrm{~h}$ half-life, 2) a condensation and coagulation scheme, 3) an oxidative scheme, and 4) a linear combination of the latter two ageing treatments. Global BC burdens are $2.15,0.15,0.11,0.21$, and $0.11 \mathrm{Tg} \mathrm{C}$ for the control run, and four ageing schemes, respectively. The $\mathrm{BC}$ lifetimes are 98.1, 6.6, 5.0, 9.5, and 4.9 days, respectively. The sensitivity of modelled BC burdens, and concentrations to the factor of two uncertainty in the emissions inventory is shown to be greater than the sensitivity to the parameterization used to represent the $\mathrm{BC}$ ageing, except for the oxidation based parameterization. A computationally efficient parameterization that represents the processes of condensation, coagulation, and oxidation is shown to simulate $\mathrm{BC}$ ageing well in the CCCma AGCM. As opposed to the globally fixed ageing time scale, this treatment of $\mathrm{BC}$ ageing is responsive to varying atmospheric composition.

Correspondence to: $\mathrm{B}$. Croft

(croft@mathstat.dal.ca)

\section{Introduction}

Aerosol particles in the atmosphere, such as black carbon (BC), have a significant influence on global climate. These particles both scatter and absorb radiation, thus impacting radiative transfer through the atmosphere (direct and semidirect effects). Additionally, aerosols act as cloud condensation and ice nuclei, which influence cloud properties (indirect effects). The first indirect effect is based on the premise that for a given amount of cloud liquid water content, increased aerosol number implies more, and smaller cloud droplets, and hence a more strongly reflective cloud. The second indirect effect suggests that a cloud with more but smaller cloud droplets will be less likely to precipitate (i.e. enhanced lifetime) due to a slower growth of the individual droplets. Black carbon aerosols have a role to play in all of these climate effects. For this reason, the concentration of $\mathrm{BC}$ aerosols must be accurately determined by atmospheric general circulation models (AGCMs).

Black carbon particles may exist in the atmosphere as either insoluble particles, or in mixtures that are considered soluble. BC in a soluble mixture will be more efficiently removed by dry and wet deposition processes, and have a shorter atmospheric residence time (Chylek et al., 1999; Hitzenberger et al., 2001; Zuberi et al., 2005). AGCMs must quantify the amount of $\mathrm{BC}$ that exists in the insoluble versus soluble/mixed state. For simplicity, many AGCMs assume that surface based sources are comprised of BC that is $80 \%$ insoluble, and 20\% soluble (Cooke et al., 1999; Lohmann et al., 1999; Koch, 2001; Chung and Seinfeld, 2002; Cooke et al., 2002). Following emission, $\mathrm{BC}$ is subject to atmospheric processes, which include oxidation, condensation and coagulation. These processes, termed the ageing processes, act to change the solubility of the $\mathrm{BC}$ aerosol. Parameterization of the $\mathrm{BC}$ ageing processes in AGCMs is key to the determination of the atmospheric abundance of this aerosol.

(C) 2005 Author(s). This work is licensed under a Creative Commons License. 
To date, many AGCMs have assumed that the conversion from insoluble to soluble $\mathrm{BC}$ follows an exponential decay process with a half-time in proximity to $24 \mathrm{~h}$ (Cooke et al., 1999; Lohmann et al., 1999; Koch, 2001; Chung and Seinfeld, 2002). This approach has an obvious limitation since decay rate should vary depending on the physical or chemical process that dominates the ageing. Coagulation should be enhanced in regions of greater total aerosol number concentration. Additionally, regions with large fossil fuel burning emissions will have higher concentrations of sulphuric and nitric acid vapours available for condensation, as compared to regions dominated by open burning emissions. The relative importance of oxidative processes is not well quantified in a global sense. However, laboratory studies have shown oxidation to play a role in the $\mathrm{BC}$ ageing process (Zuberi et al., 2005; Decesari et al., 2002; Pöschl et al., 2001).

The focus of this study is to examine the relative impact of several parameterizations of the $\mathrm{BC}$ ageing process on the $\mathrm{BC}$ burdens, concentrations and lifetimes. To this end, four separate parameterizations are employed in the development version of the Canadian Centre for Climate modelling and analysis (CCCma) AGCM. These will be discussed in greater depth in the model description section. One parameterization is based on condensation and coagulation processes (Riemer et al., 2004a). This parameterization was originally designed for use in regions dominated by fossil fuel burning. A second parameterization is based exclusively on oxidation, following Pöschl et al. (2001) and Tsigaridis and Kanakidou (2003). A third and novel parameterization assumes that the processes of oxidation, condensation, and coagulation may be treated in an additive manner. These three parameterizations are compared to the parameterization used by many AGCMs, which assumes a fixed e-folding time, and additionally to a control simulation that assumes no ageing occurs.

An overview of the developmental version of the 4th generation CCCma AGCM, and the details of the various treatments for BC ageing are in Sect. 2. In Sect. 3, the modelled $\mathrm{BC}$ burdens, concentrations and lifetimes are presented. A comparison is made between the separate parameterizations, which shows the relative importance of the physical and chemical processes involved in $\mathrm{BC}$ ageing. This section also includes comparisons with previous modelling studies, and with another emission inventory. As well, the sensitivity of the modelled $\mathrm{BC}$ burdens to the factor of two uncertainty in the emission inventories (Bond et al., 2004), and the model resolution is examined. Section 4 shows comparisons with observed surface layer concentrations for several sites in both continentally influenced, and remote locations.

\section{Model description}

A developmental version of the fourth generation CCCma AGCM has been used for this study (von Salzen et al.,
$2005)^{1}$. The spectral transform method is used with triangular truncation at wave number 47 (T47) to represent the horizontal spatial structure of temperature, specific humidity, surface pressure, vorticity, divergence, and the mass mixing ratios of cloud liquid and ice water, and chemical tracers. The model equations are solved on 35 vertical levels using a hybrid pressure-sigma grid. Physical terms, and nonlinear processes are evaluated on a horizontal grid at a resolution of $3.75 \times 3.75^{\circ}$. The time step used is $20 \mathrm{~min}$.

An interactive sulphur cycle is included in the model (Lohmann et al., 1999; von Salzen et al., 2000). Sulphate aerosol concentrations affect clear-sky radiative transfer directly and indirectly via the first and second indirect effect in stratiform clouds (Haywood and Boucher, 2000; Lohmann and Feichter, 1997). In the model, the tracer quantity that is transported is the transformed variable,

$$
s=\left\{\begin{array}{cl}
\frac{q_{0}}{\left[1+p \ln \left(q_{0} / q\right)\right]^{1 / p}}, & \text { if } q<q_{0}, \\
q, & \text { if } q \geq q_{0},
\end{array}\right.
$$

where $q$ is the physical variable (i.e. specific humidity, chemical tracer mixing ratios, and cloud liquid and ice water), and $q_{0}$ and $p$ are constants. This is a generalization of the hybrid variable transformation proposed by Boer (1995). The use of this transformed variable alleviates to a considerable extent the undesirable overshoots and undershoots that can occur when spectrally transporting rapidly varying functions (Merryfield and Holloway, 2003). In particular, unphysical negative values, and the undesirable effects that accompany them are largely suppressed. Although the transport algorithm is conservative with respect to $s$, the physical variable $q$ no longer is precisely conserved under transport. However, by judiciously choosing $q_{0}$ and $p$, the degree of global non-conservation can be effectively controlled. Therefore, $q_{0}$ and $p$ are assigned separately for each tracer according to a criterion that non-conservation errors do not exceed a certain threshold. The model also includes a method that locally corrects for any residual changes in global tracer mass that may be caused by transport of the hybrid variable. The AGCM includes an updated version of the dust source flux parameterization described in Reader et al. (1999), with a single global source strength parameter, dependence on wind friction speed rather than wind speed, and improved soilmoisture dependence.

\subsection{Carbon aerosol simulation}

The two prognostic variables for black carbon $(\mathrm{BC})$ in the AGCM are the insoluble $\mathrm{BC}$ and the soluble/mixed $\mathrm{BC}$ mass mixing ratios. Soluble/mixed $\mathrm{BC}$ is the form that can act as cloud condensation or ice nuclei. Black carbon emissions are from Bond et al. (2004) for the fossil fuel and bio-fuel

\footnotetext{
${ }^{1}$ von Salzen, K., McFarlane, N. A., and Lazare, M.: The role of shallow convection in the water and energy cycles of the atmosphere, Climate Dynamics, in press, 2005.
} 

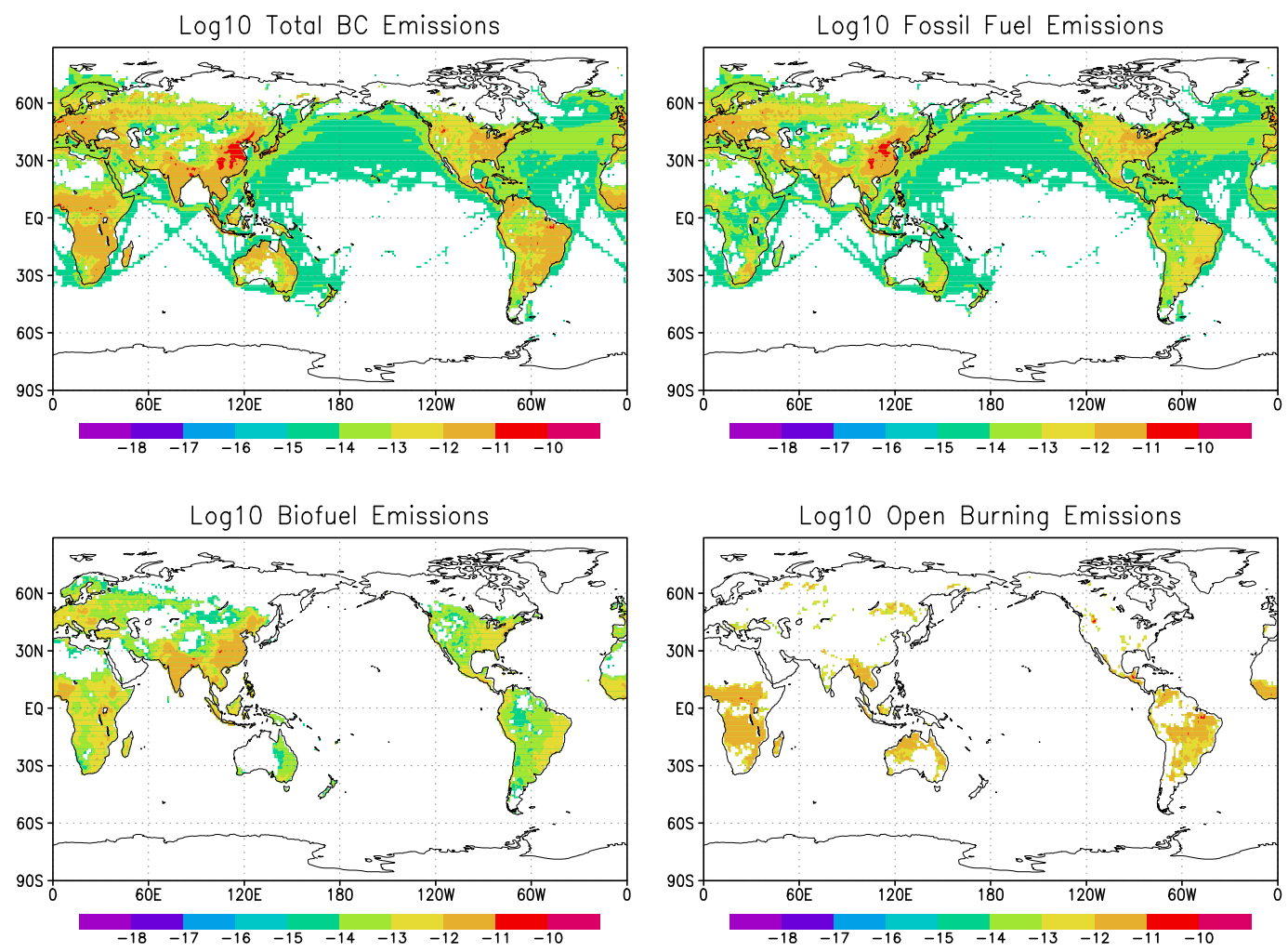

Fig. 1. Log 10 of annual mean column black carbon emissions $\left(\mathrm{kg} \mathrm{C} / \mathrm{m}^{2} / \mathrm{s}\right)$ from Bond et al. (2004) for fossil fuel and bio-fuel burning, and from van der Werf et al. (2003) for open burning.

burning emissions, and from van der Werf et al. (2003) for open burning, including large agricultural fires. These emission inventories are for the year 1996 and 2000, respectively. The annual $\mathrm{BC}$ emissions are 3.04, 1.63, and 3.32 Tg C/yr for fossil fuel, bio-fuel, and open burning, respectively. Figure 1 shows the global distribution of column BC emissions. The open burning emissions are emitted into layers up to $6 \mathrm{~km}$ above the surface, whereas fossil fuel and bio-fuel are into layers up to $100 \mathrm{~m}$. The distribution of these emissions into vertical layers is shown in the four panels of Fig. 2.

The emissions are assumed to be $80 \%$ insoluble and $20 \%$ soluble/mixed. Compounds may become attached to the black carbon and undergo chemical processes. This alters the solubility of the aerosol. These processes are termed ageing. Many models assume ageing to be an exponential decay process with a fixed half life close to $24 \mathrm{~h}$ (Cooke et al., 1999; Lohmann et al., 1999; Chung and Seinfeld, 2002).

The aerosols are removed from the atmosphere by the processes of wet and dry deposition. The dry deposition flux is proportional to the $\mathrm{BC}$ concentration in the lowest model layer and a dry deposition velocity. This is $0.025 \mathrm{~cm} / \mathrm{s}$ over dry surfaces and $0.2 \mathrm{~cm} / \mathrm{s}$ over wetted surfaces for the soluble/mixed BC, and $0.025 \mathrm{~cm} / \mathrm{s}$ over all surfaces for the insoluble BC. The equation for dry deposition is

$F_{d}=\rho \cdot M_{i} \cdot V_{d}$ where $\rho$ is the air density, $M_{i}$ is the mass mixing ratio of the tracer and $V_{d}$ is the dry deposition velocity that depends on surface type.

The wet deposition is proportional to the precipitation formation rate (Feichter et al., 1996; Lohmann et al., 1999; von Salzen et al., 2000). There is both in-cloud and below cloud scavenging. Only the soluble/mixed BC is subject to in-cloud scavenging. For the convective clouds, the in-cloud scavenging rate for soluble/mixed $\mathrm{BC}$ has the form,

$\frac{\delta M_{u} C_{u}}{\delta z}=-C_{o} \cdot f_{o} \cdot M_{u} \cdot C_{u}$

where $C_{o}$ accounts for the conversion from cloud water to rainwater in the timestep following Lord (1982), $f_{o}$ is the fraction of the tracer dissolved in the cloud droplets and is assumed to be unity for all particles larger than a certain critical size, $M_{u}$ is the upward mass flux of air in the convective region and $C_{u}$ is the concentration of the tracer in the updraft region. The CCCma AGCM does not include below cloud scavenging for the convective clouds. The stratiform in-cloud scavenging of soluble/mixed $\mathrm{BC}$ over the timestep, $\delta t$, is given by,

$\frac{\delta C}{\delta t}=a \frac{H C_{c}}{\tau}$ 

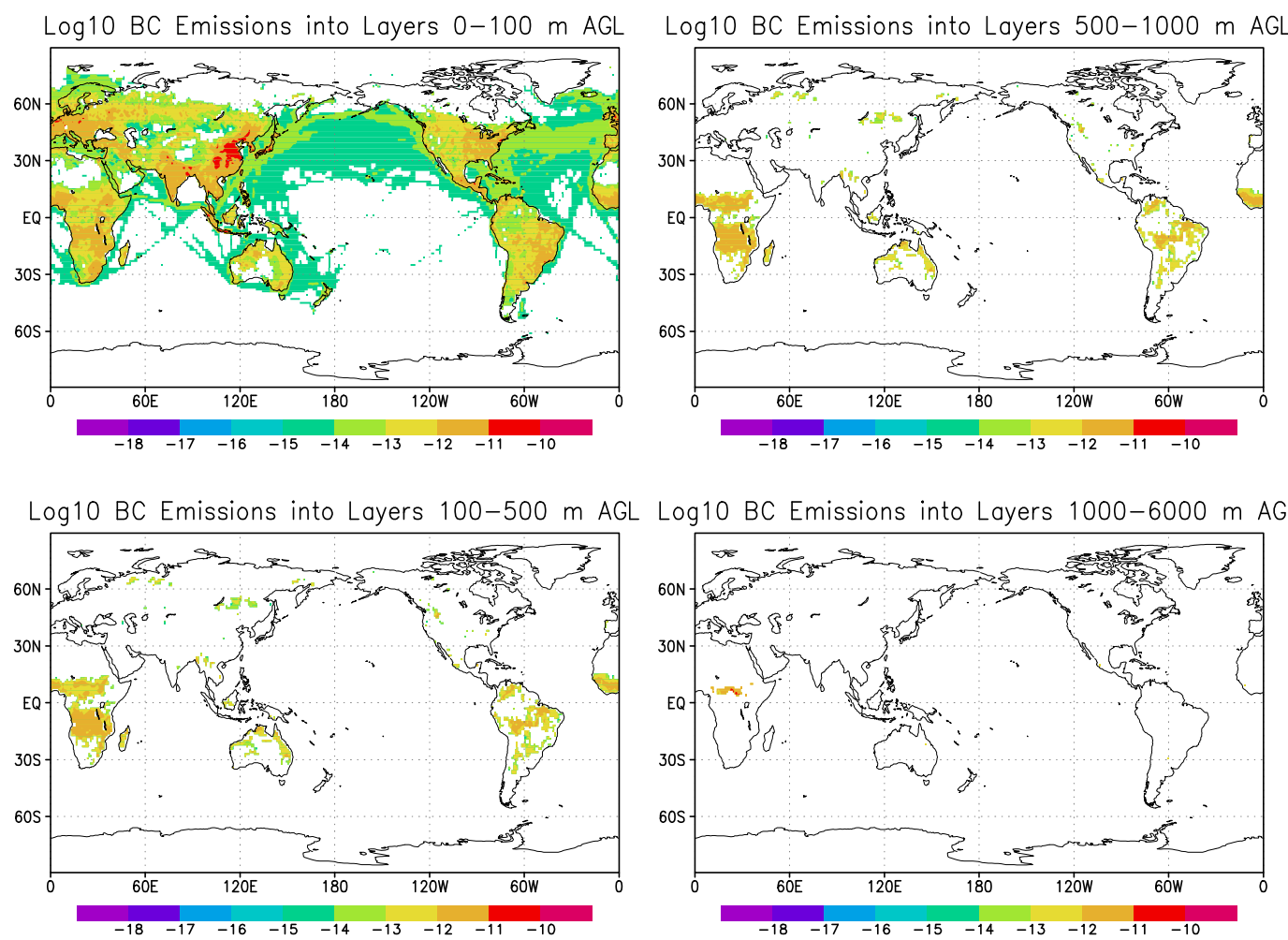

Fig. 2. $\log _{10}$ of annual mean black carbon emissions $\left(\mathrm{kg} \mathrm{C} / \mathrm{m}^{2} / \mathrm{s}\right)$ into layers from surface to $100 \mathrm{~m}, 100-500 \mathrm{~m}, 500-1000 \mathrm{~m}$, and $1000-$ $6000 \mathrm{~m}$ from Bond et al. (2004) for fossil fuel and bio-fuel burning, and from van der Werf et al. (2003) for open burning.

where $C$ is the tracer concentration, $C_{c}$ is the in-cloud concentration of the tracer, $a$ is the cloud fraction, and $H$ is a Henry's law constant. $\tau$ is given by

$$
\tau=\frac{L W C}{Q_{a u t}+Q_{a c c}}
$$

where $L W C$ is the cloud liquid water content, $Q_{a u t}$ is the rate of autoconversion of cloud liquid water, and $Q_{a c c}$ is the rate of accretion of cloud liquid water by rain. The stratiform below cloud scavenging gives the change in the tracer concentration over the timestep, $\delta t$, as,

$\delta C=k \cdot C \cdot K_{o} \cdot P_{r} \cdot \delta t$

where the collection efficiency, $K_{o}$, is $0.3, \mathrm{P}_{r}$ is the precipitation rate, $\mathrm{C}$ is the tracer concentration, and the constant $k$ is $5.2 \mathrm{~m}^{3} \mathrm{~kg}^{-1} \mathrm{~s}^{-1}$. The below cloud scavenging efficiency is assumed to be the same for both the insoluble, and soluble/mixed BC, and sulphate. There remains uncertainty with regard to the magnitude and sign of the bias that this assumption may cause in the modelled removal rates.

In this study, several physically and chemically based treatments for $\mathrm{BC}$ ageing are examined using the CCCma AGCM. Three processes that contribute to BC ageing are, coagulation with soluble aerosols, condensation of sulphuric and nitric acid gases onto the aerosol, and $\mathrm{BC}$ aerosol surface coating oxidation by ozone. The condensation of semi- volatile organic gases onto the $\mathrm{BC}$ aerosol is an additional process that is neglected in this study, but may well be of importance.

Using a mesoscale model, Riemer et al. (2004a) represented the processes of condensation and coagulation over a region roughly the size of one AGCM grid box, but in more explicit detail than an AGCM permits. These authors find that in a region dominated by significant fossil fuel burning emissions, the process of condensation is dominant during the day, and coagulation is dominant at night. Ageing by the process of condensation is found to be very rapid. During the day, the e-folding time for the ageing process was found to be $8 \mathrm{~h}$ below $250 \mathrm{~m}$, and above this, and up to $2-3 \mathrm{~km}$, the e-folding time was $2 \mathrm{~h}$. During the night time, Riemer et al. (2004a) found that the e-folding time, $\tau$, in hours, was dominated by the process of coagulation, and may be parameterized as a function of the internally mixed aerosol number concentration $\left(N_{a}\right)$,

$\tau=\exp \left(-a N_{a}+b\right)$

where $N_{a}$ is less than $4100 \mathrm{~cm}^{-3}$, and as

$\tau=-c+d N_{a}$,

where $N_{a}$ is more than $4100 \mathrm{~cm}^{-3}$. The constants, $a$, $b, c$, and $d$, are $2.3012 \cdot 10^{-4} \mathrm{~cm}^{3}, 4.4428,3.8585 \mathrm{~h}$, and 
$1.48 \cdot 10^{5} \mathrm{~h} \mathrm{~cm}^{-3}$, respectively. Another form of this relation has more recently been proposed as

$$
\tau=\frac{a}{N_{a}}+\frac{b}{N_{a}^{2}}
$$

by Riemer et al. (2004b), The constants, a and b, are $6 \cdot 10^{4} \mathrm{~h} \mathrm{~cm}^{-3}$ and $3 \cdot 10^{8} \mathrm{~h} \mathrm{~cm}^{-6}$, respectively. This relation is not used here, since this was not available at the time that this study was conducted. However, since both forms of this relation are very similar over the range of $N_{a}$ that predominates globally, not much difference is expected in the results. A preliminary run of a simulation using Equation 8 (not shown) gives a global and annual mean BC burden that differs by less than $0.1 \%$ from an otherwise identical simulation that uses Eqs. (6) and (7). The Riemer et al. (2004a) parameterization for both day-time and night-time ageing is applied in the CCCma AGCM. The results of these experiments are called COND-COAG. Note that the day-time efolding time is assumed to be $2 \mathrm{~h}$ for all grid boxes that are $250 \mathrm{~m}$ or more above ground ground level, and $8 \mathrm{~h}$ for all grid boxes below this altitude. Table 1 shows a summary of all model simulations conducted.

The zonal mean internally mixed aerosol number concentration is shown in Fig. 3, for the FIX-LIFE simulation. Coagulation is enhanced in regions of greater aerosol number following the Riemer et al. (2004a) parameterization. In the COND-COAG simulation, the internally mixed aerosol is assumed to include all of the mass of sulphate, soluble/mixed $\mathrm{BC}$ and $\mathrm{OC}$, and accumulation mode dust and sea salt. The conversion from mass mixing ratio to number concentration is made assuming a log-normal size distribution with a mode radius of $0.069 \mu \mathrm{m}$, and standard deviation of 1.538 following Lesins and Lohmann $(2005)^{2}$. The lognormal assumption gives the following relation between number concentration, $N_{a}$, and mass mixing ratio,

$N_{a}=\frac{\rho_{a} M}{\rho_{i}}\left(\frac{\pi}{6} D^{3} \exp (9 / 2) \ln ^{2} \sigma_{g}\right)^{-1}$

where $\rho_{a}$ is the air density, $M$ is the mass mixing ratio, $\mathrm{D}$ is the modal diameter and $\sigma_{g}$ is the standard deviation for the lognormal distribution. $M$ is the sum of the $\mathrm{BC}, \mathrm{OC}$, sulphate, dust, and sea salt mass mixing ratios. $\rho_{i}$ is the collective density, weighted by the density of the respective components of the internally mixed aerosol.

Compounds may coat the $\mathrm{BC}$ aerosol, and then become oxidized (Pöschl et al., 2001). A pseudo-first order decay rate coefficient for the rate of oxidation of a $\mathrm{BC}$ coating (benzo[a]pyrene) by ozone has been determined from laboratory studies by Pöschl et al. (2001). These authors find that the decay rate coefficient, $k$, is dependent on the number of available sites on the $\mathrm{BC}$ aerosol, and the sticking coeffi-

\footnotetext{
${ }^{2}$ Lesins, G. and Lohmann, U.: Using MODIS and AERONET to determine GCM aerosol size, J. Atmos. Sci., submitted, 2005.
}

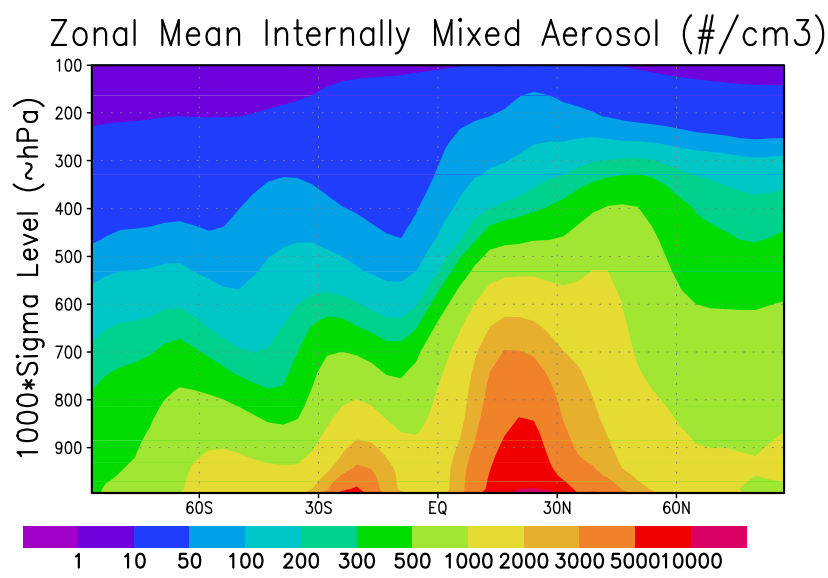

Fig. 3. Zonal and annual mean internally mixed aerosol number concentration (number $\mathrm{cm}^{-3}$ ). Vertical axis is model hybrid sigma level scaled by 1000 , but roughly corresponds to $\mathrm{hPa}$.

cients, residence times, and concentration of both ozone and water vapour molecules;

$k=\frac{K_{\infty} k_{\mathrm{O}_{3}}\left[\mathrm{O}_{3}\right]}{1+k_{\mathrm{O}_{3}}\left[\mathrm{O}_{3}\right]+k_{\mathrm{H}_{2} \mathrm{O}}\left[\mathrm{H}_{2} \mathrm{O}\right]}$,

where $K_{\infty}$ is the pseudo-first-order decay rate coefficient in the limit of high $\mathrm{O}_{3}\left(0.015 \mathrm{~s}^{-1}\right)$ and $k_{\mathrm{O}_{3}}$ and $k_{\mathrm{H}_{2} \mathrm{O}}$ are the adsorption rate coefficients of ozone and water vapour, respectively. These are given by,

$k_{i}=\frac{S_{o, i} \omega_{i}}{4[S S]_{S}} \tau_{i}$,

where $S_{o, i}$ is the sticking coefficient of $\mathrm{O}_{3}$ and $\mathrm{H}_{2} \mathrm{O}$ $\left(3.3 \cdot 10^{-3}\right.$ and $0.4 \cdot 10^{-3}$, respectively), $\omega_{i}$ is the mean thermal velocity, $[S S]_{S}$ is the surface concentration of adsorption sites $\left(5.7 \cdot 10^{14} \mathrm{~cm}^{-2}\right)$, and $\tau_{i}$ is the mean residence time of $\mathrm{O}_{3}$ and $\mathrm{H}_{2} \mathrm{O}$ on the surface sites $\left(5 \mathrm{~s}\right.$ and $3 \cdot 10^{-3} \mathrm{~s}$, respectively). Water vapour acts to impede the oxidation by ozone since these gases compete to occupy the available sites on the aerosol. The lifetime of the $\mathrm{BC}$ coating with respect to oxidation was found by these authors to be in the order of 5 to $15 \mathrm{~min}$ for dry versus humid conditions. In poorly oxidizing environments, this lifetime will be longer. This parameterization is tested in the simulation called OXID.

Additionally, it is important to note that the rate of oxidation of a surface coating is not synonymous with the rate of production of a soluble aerosol particle. In particular, the material to be oxidized is not likely to be distributed homogeneously over the $\mathrm{BC}$ aerosol. In reality, there are physical shielding effects that slow the rate of the ageing. BC aerosols are not uniform spheres, but have been observed to exhibit a chain structure that collapses to a clump like structure (Abel et al., 2003). Species that are deposited on the $\mathrm{BC}$ aerosol could be physically shielded from the oxidants by the layering of both themselves and the $\mathrm{BC}$ as suggested 
Table 1. Summary of simulations conducted showing assumptions regarding the BC ageing process, and emissions inventory used.

\begin{tabular}{|c|c|c|}
\hline Simulation Name & Emission inventory & Ageing e-folding timescale \\
\hline NO-AGE & Bond et al.(2004) - van der Werf(2003) & $\infty$ \\
\hline FIX-LIFE & Bond et al.(2004) - van der Werf(2003) & $35 \mathrm{~h}$ \\
\hline COND-COAG & Bond et al.(2004) - van der Werf(2003) & 2 or $8 h$ (day), $\propto N_{a}$ (night) \\
\hline OXID & Bond et al.(2004) - van der Werf(2003) & $(0.01 k)^{-1} \propto\left[\mathrm{H}_{2} \mathrm{O}\right],\left[\mathrm{O}_{3}\right]$ \\
\hline COND-COAG-OXID & Bond et al.(2004) - van der Werf(2003) & linear sum COND-COAG,OXID \\
\hline COAG & Bond et al.(2004) - van der Werf(2003) & $\propto \mathrm{N}_{a}$ \\
\hline FIX-LIFE2 & Penner et al.(1993) - Liousse et al.(1996) & $35 \mathrm{~h}$ \\
\hline MODB-COND-COAG & Bond et al.(2004) - van der Werf(2003) & $\mathrm{COAG}$ if $\mathrm{BC} / \mathrm{SO}_{4} \geq 4$ else COND-COAG \\
\hline MODR-COND-COAG & Bond et al.(2004) - van der Werf(2003) & COAG if $\mathrm{N}_{a} \leq 300$ else COND-COAG \\
\hline $1.0 \mathrm{x}$ EMISS & Bond et al.(2004) - van der Werf(2003) & $35 \mathrm{~h}$ \\
\hline $0.5 \times$ EMISS & Scale Bond et al.(2004) - van der Werf(2003) by 0.5 & $35 \mathrm{~h}$ \\
\hline $2.0 \times$ EMISS & Scale Bond et al.(2004) - van der Werf(2003) by 2.0 & $35 \mathrm{~h}$ \\
\hline $\mathrm{OXID}(0.001)$ & Bond et al.(2004) - van der Werf(2003) & $(0.001 k)^{-1}$ \\
\hline $\mathrm{OXID}(0.1)$ & Bond et al.(2004) - van der Werf(2003) & $(0.1 k)^{-1}$ \\
\hline
\end{tabular}

Table 2. Global and annual mean black carbon burdens, lifetimes, and deposition rates.

\begin{tabular}{llllll}
\hline & NO-AGE & FIX-LIFE & COND-COAG & OXID & COND-COAG-OXID \\
\hline Emission (Tg C/yr) & 8.01 & 8.01 & 8.01 & 8.01 & 8.01 \\
Burden (Tg C) & 2.153 & 0.145 & 0.109 & 0.209 & 0.108 \\
Lifetime (days) & 98.1 & 6.6 & 5.0 & 9.5 & 4.9 \\
Wet dep (Tg C/yr) & 5.07 & 6.09 & 5.99 & 6.00 & 5.98 \\
Dry dep (Tg C/yr) & 2.64 & 1.92 & 2.02 & 2.01 & 2.03 \\
\hline
\end{tabular}

by Pöschl et al. (2001). There is little guidance to date on how to model the effects of physical shielding. As an initial approach, the reaction rate constant is scaled by a factor in the simulation OXID. The sensitivity to this scaling factor is considered in Sect. 3, and comparisons with surface observations are shown in Sect. 4.

To date, no AGCM studies have attempted to combine the processes of coagulation, condensation, and oxidation. This will be the first study to do so with the simulation CONDCOAG-OXID. As a first step, it is assumed that these processes can be combined in a linearly additive manner. This may under-estimate the ageing time scale since this assumes that the processes occur entirely independently, and do not compete with each other on time scales in the order of one model time-step. Unfortunately, there is no laboratory evidence available to suggest how these processes interact. Table 1 summarizes the simulations conducted in this study, and shows the assumptions made about the ageing time-scale, and the emissions inventories used.

\section{Burdens, concentration and lifetimes}

In total five primary simulations were conducted with the CCCma AGCM. All results shown are time averages from 3year model runs following a 5-month spin up period, and use monthly mean climatological sea surface temperatures that are representative for the second half of the 20th century. The first simulation (NO-AGE) assumes no ageing i.e. there is no conversion from insoluble to soluble/mixed BC. This simulation serves to motivate the work, and demonstrates that it is important to represent the ageing process in a AGCM, but is a very unlikely scenario. The second simulation (FIX-LIFE) assumes an exponential decay of the insoluble $\mathrm{BC}$ to the soluble/mixed state with a fixed half life of $24 \mathrm{~h}$ (i.e. an e-folding time of $35 \mathrm{~h}$ ). The remaining simulations are COND-COAG, OXID and COND-COAG-OXID, as discussed in the previous section and outlined in Table 1. 

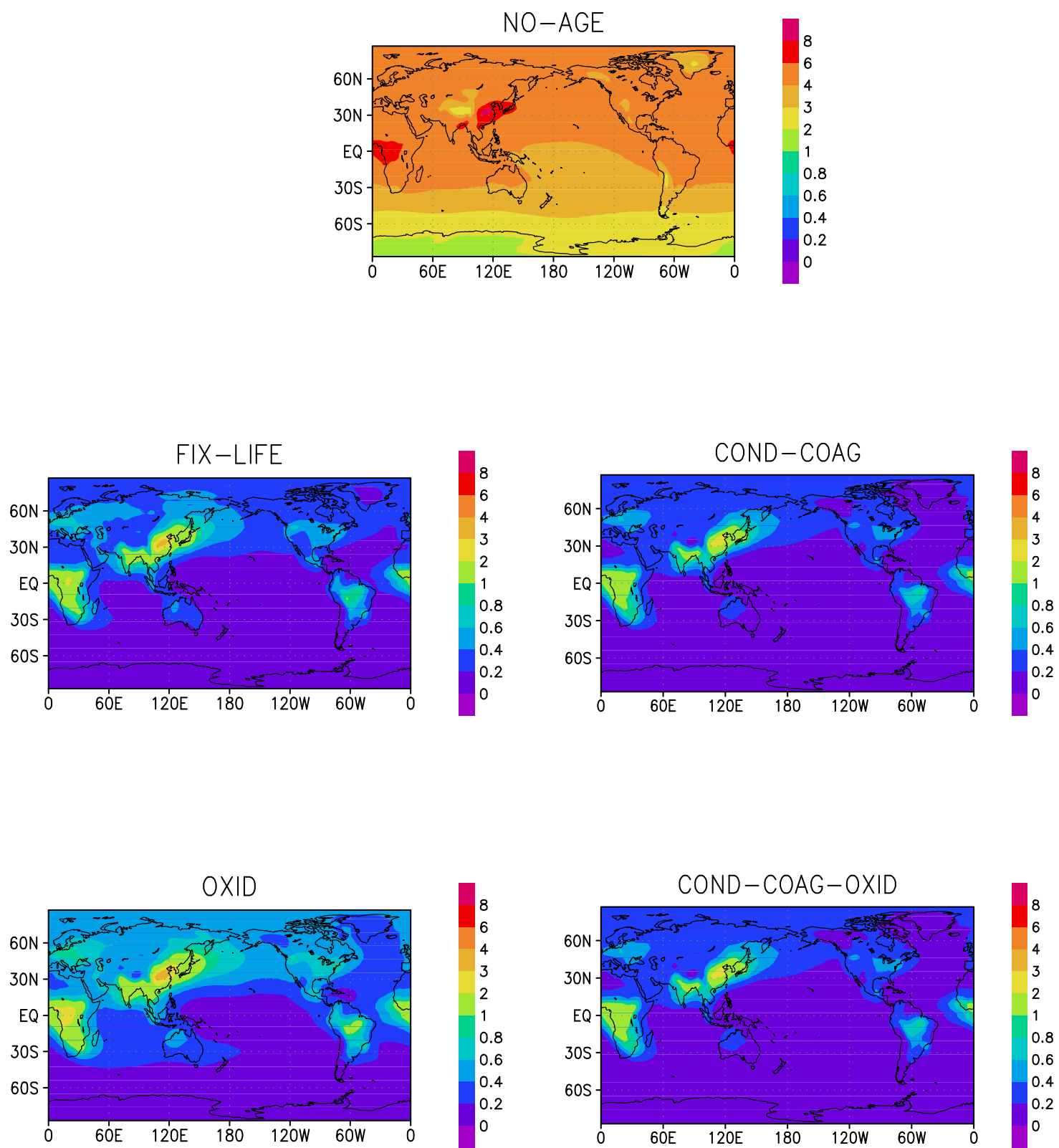

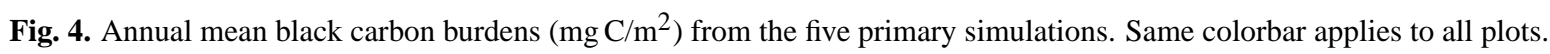

The global and annual mean BC burdens, lifetimes, and deposition rates for the five simulations are shown in Table 2. Geographical distributions of the burdens are shown in Fig. 4. The NO-AGE simulation gives a global and annual mean burden that is more than an order of magnitude higher than any of the other simulations. This suggests that the ageing parameterization is clearly important in an AGCM. This high burden is predicted because a higher percentage of the total $\mathrm{BC}$ resides in the insoluble state. Insoluble $\mathrm{BC}$ is less efficiently removed by the process of wet deposition, the primary removal process. Note that wet and dry deposition account for roughly 75 and 25 percent of the total deposi- tion, respectively, in all of the simulations except NO-AGE. Aside from NO-AGE, the simulations give burdens that are all within a factor of two of each other. The lifetime of BC is found to be on the order of one week. The exception is the NO-AGE simulation that has a lifetime close to three months.

The $\mathrm{BC}$ ageing is fastest in the COND-COAG and CONDCOAG-OXID simulations. The ageing in these simulations is primarily controlled by the assumption that the day-time ageing time-scale is $2 \mathrm{~h}$ in all grid boxes that are $250 \mathrm{~m}$ or more above ground level, and $8 \mathrm{~h}$ for grid boxes below this height. This time-scale is due to condensation of sulphuric acid, assuming that sulphate production and condensation dominate 

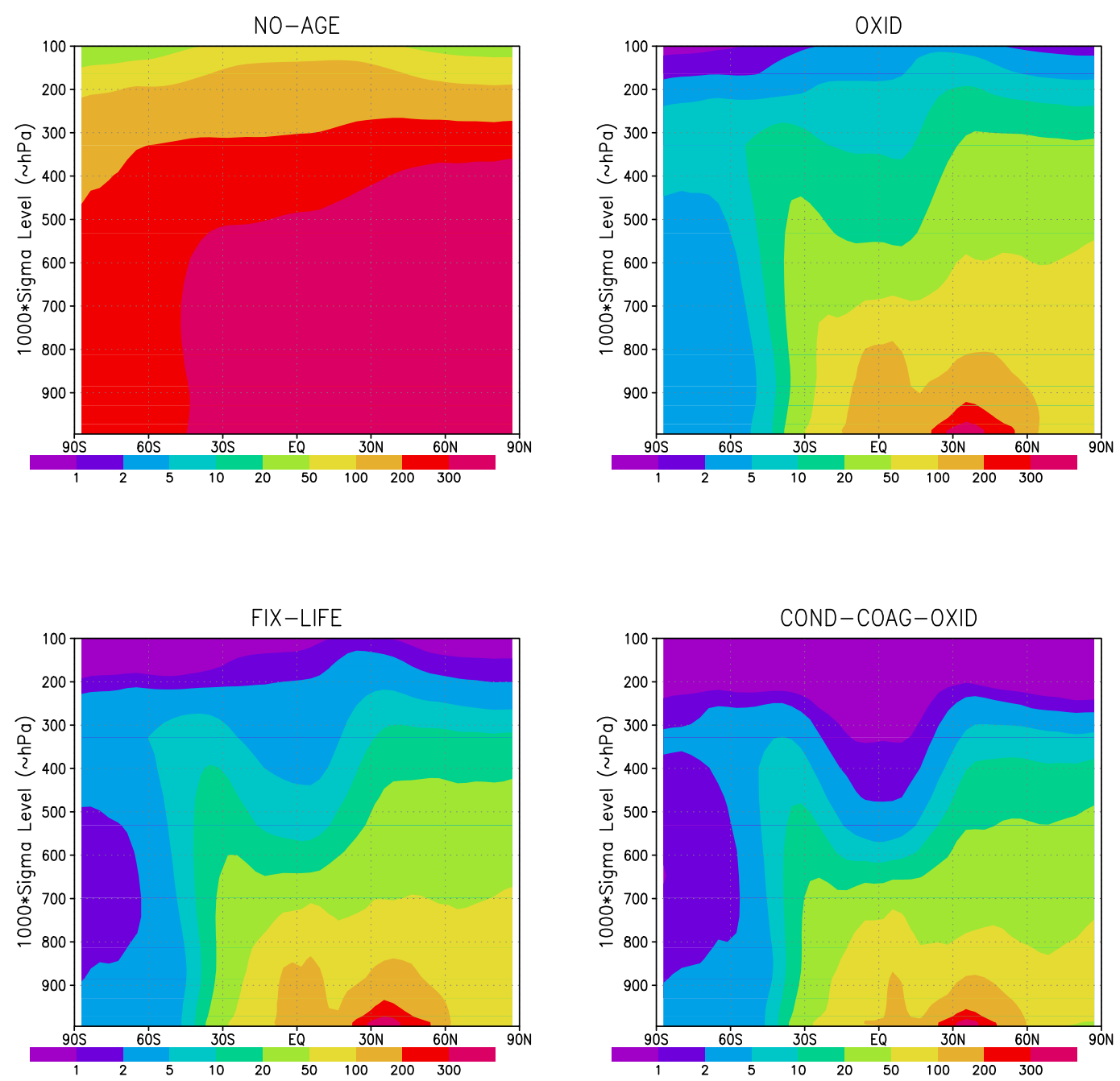

Fig. 5. Zonal and annual mean $\mathrm{BC}$ concentrations $\left(\mathrm{ng} / \mathrm{m}^{3}\right)$ from four of the simulations. Vertical axis is model hybrid sigma level scaled by 1000 , but roughly corresponds to $\mathrm{hPa}$.

the day-time ageing, but shut off at night. This follows the work of Riemer et al. (2004a) where the process of condensation is modelled as in Binkowski and Shankar (1995). There does remain uncertainty with regard to how the condensation of sulphuric acid varies depending on the composition of the pre-existing aerosol. We also note that Riemer et al. (2004a) ignored the in-cloud production of sulphate that could occur at night. Thus, the night-time ageing, due to coagulation alone, might be too slow. One might also question the use of this fixed day-time e-folding time in remote regions where sulphate production is lower, and further in regions where sulphate production is low, but BC concentrations are still relatively high, such as in areas where open burning is the dominant BC source as opposed to fossil fuel burning. These considerations are further investigated in the following subsection.

The results of the COND-COAG and COND-COAGOXID simulations are very similar since to the contribution of oxidation to the $\mathrm{BC}$ ageing process is modelled to be quite small. This small contribution was modelled for two primary reasons. Firstly, previous studies have suggested that this contribution is small (Saathoff et al., 2003). Secondly, comparison of the BC concentrations from the COND-COAG simulation with observations, as shown in Sect. 4, suggests that the added effect of oxidative processes should not be too large. Sensitivity to the assumptions regarding the oxidation parameterization is shown in a following subsection. A parameterization based on oxidation of the organic coating of BC has been studied previously by Tsigaridis and Kanakidou (2003) using a global 3-dimensional chemistry/transport model. The calculated lifetimes of the primary hydrophobic carbonaceous aerosol due to oxidation were smaller than in this study. Tsigaridis and Kanakidou (2003) reported these lifetimes to be in the same order of magnitude as those of Cooke et al. (1999) i.e. 1.15 days, but with high spatial differences largely due to the water vapour distribution. However, 

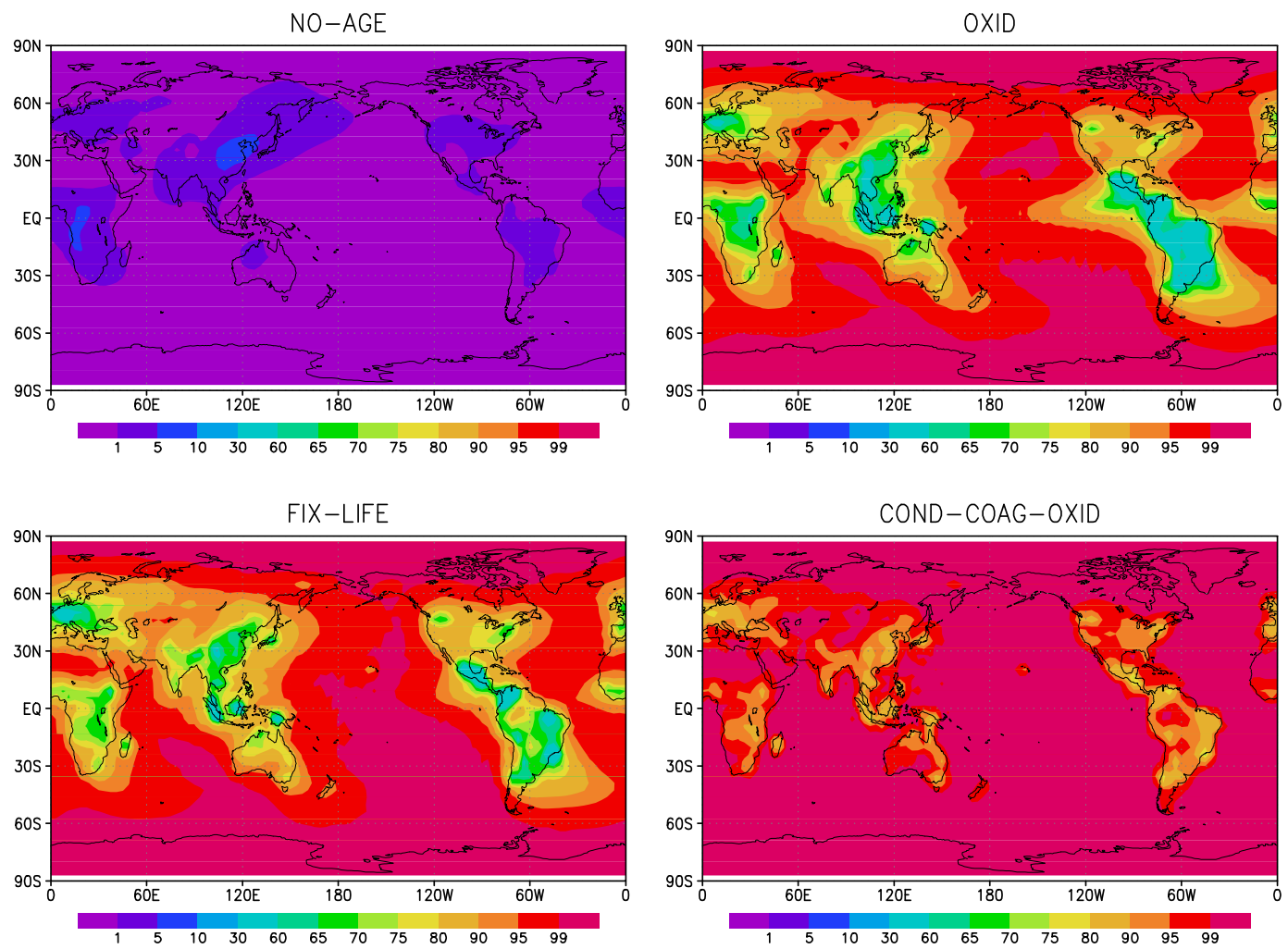

Fig. 6. Annual mean percent of $\mathrm{BC}$ existing in the soluble/mixed state as determined by the ratio of column burdens from four of the $\mathrm{BC}$ ageing simulations.

one must bear in mind that this result would be sensitive to these authors assumptions regarding the aerosol size, and the thickness of oxidized coating required to consider the aerosol hydrophylic. The validity of these assumptions on a global scale needs further justification before one could definitively conclude on the contribution of oxidation to the $\mathrm{BC}$ ageing process, and likewise for this study.

Figure 5 shows the zonal mean $\mathrm{BC}$ concentrations. The trends seen here are similar to those seen in the previous figure. The peak concentrations occur near the surface in the midlatitudes of the Northern Hemisphere due to fossil fuel burning. A secondary peak near the equator is associated with open and bio-fuel burning. In the OXID simulation, the $\mathrm{BC}$ concentrations decay slower with height than in the other simulations, except for NO-AGE. This reflects the slower ageing due to oxidation. Concentrations decay the fastest with height in the COND-COAG-OXID simulation. This difference will have a potentially significant impact on estimates of the indirect effect due to ice nucleation in the upper troposphere since in the FIX-LIFE and OXID simulations have considerably more $\mathrm{BC}$ mass to act as ice nuclei (Lohmann, 2002) in the upper troposphere.

Figure 6 shows the fraction of the total BC that resides in the soluble/mixed state for four of the simulations as determined by taking the ratio of column burdens. We can see that in the NO-AGE simulation less than $10 \%$ of the BC aerosol exists in a soluble state. The $20 \%$ of $\mathrm{BC}$ emissions assumed to be soluble/mixed has been efficiently removed by the wet deposition processes. In all other simulations, over the oceans the percent in the soluble state is mostly over $90 \%$. Over the continents, the transfer of $\mathrm{BC}$ to the soluble mixed state is much faster in the COND-COAG-OXID simulation as compared to the FIX-LIFE simulation. In the FIX-LIFE simulation, extensive continental zones exist where only about $60 \%$ of the $\mathrm{BC}$ is in the soluble mixed state. Whereas in the COND-COAG-OXID simulation, continental $\mathrm{BC}$ is generally in excess of $80 \%$ in the soluble mixed state. This will have implications on estimates of the semidirect and indirect effect of the $\mathrm{BC}$ aerosols (Lohmann and Feichter, 2005), since only the portion of BC in the soluble mixed state can act as cloud condensation nuclei.

\subsection{Sensitivity to condensation and coagulation parameter- ization}

This subsection examines the sensitivity of the BC burdens to the condensation and coagulation parameterizations. The Riemer et al. (2004a) parameterization, used in the COND-COAG simulation, was originally developed for regions dominated by fossil fuel burning. The question arises, how appropriate is the $2 \mathrm{~h}$ day-time e-folding time in 1 ) 

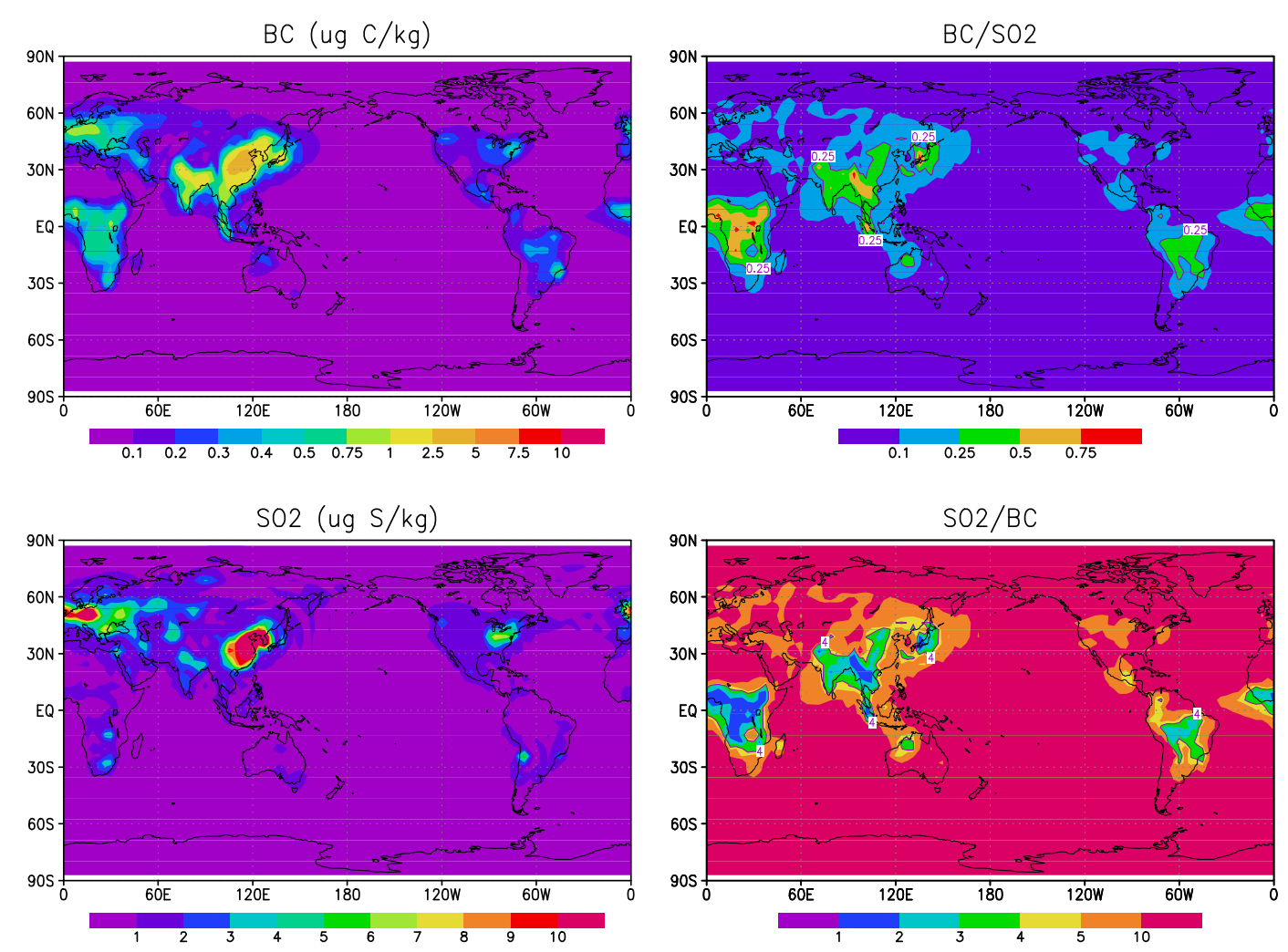

Fig. 7. Annual mean surface layer $\mathrm{BC}$ and $\mathrm{SO}_{2}$ mass mixing ratios $(\mu \mathrm{g} \mathrm{C} / \mathrm{kg}$ air and $\mu \mathrm{g} \mathrm{S} / \mathrm{kg}$ air, respectively) from the FIX-LIFE simulation are shown on left. Surface layer black carbon to $\mathrm{SO}_{2}$ ratio $(\mathrm{kg} \mathrm{C} / \mathrm{kg} \mathrm{S})$, and inverse are shown on right, and regions dominated by open and bio-fuel burning are enclosed within the labelled contours.

remote regions away from $\mathrm{BC}$ emission sources, and 2) regions dominated by open and bio-fuel burning? The CONDCOAG simulation may under-estimate burdens in these regions since there is less sulphuric acid available for condensation there. To give an upper bound on the $\mathrm{BC}$ burdens due to these concerns, two sensitivity simulations are conducted, MODR-COND-COAG and MODB-COND-COAG.

The MODR-COND-COAG simulation assumes no ageing due to condensation in remote regions, i.e. where the internally mixed aerosol number concentration is less than $300 \mathrm{~cm}^{-3}$ (Peng et al., 2002). Instead, the coagulation parameterization is applied during the day-time, as well as during the night-time in these relatively cleaner, and remote regions. In the non-remote regions, the day-time condensation parameterization remains unmodified. Note that the modelled number concentrations are high in comparison to certain observations (Peng et al., 2002). This is partly due to the choice of one globally applicable mode radius for the log-normal distribution. This radius is relatively low for regions dominated by sea salt and dust aerosols (see Hess et al., 1998). However, this mode radius was used since this was one of the only values for a global mode radius available. As a result, the $\mathrm{BC}$ burden in the MODR-COND-COAG simulation might err towards being too low, since less regions fall into the remote category than if the modelled number concentrations were lower.
The MODB-COND-COAG is a sensitivity test applied to regions dominated by open and bio-fuel burning. In these regions, $\mathrm{BC}$ mass concentrations are high, but $\mathrm{SO}_{2}$ mass concentrations are relatively much lower (Hobbs et al., 2003; Abel et al., 2003). Thus, relatively less sulphuric acid vapour should be available to contribute to the $\mathrm{BC}$ ageing than in regions where fossil fuel emissions dominate. From a theoretical standpoint Kanakidou et al. (2005) have shown that the ageing time-scale due to condensation should be proportional to the ratio of the mass of the insoluble aerosols over the the sulphate production rate. Assuming the sulphate production rate to be proportional to the $\mathrm{SO}_{2}$ concentration, a $\mathrm{BC} / \mathrm{SO}_{2}$ ratio of 0.25 or greater is used to identify these regions of open and bio-fuel burning where ageing by sulphuric acid condensation is expected to be less. In these areas, as an extreme case, the day-time ageing due to condensation is assumed to be negligible, and instead the coagulation parameterization is applied throughout the diurnal cycle. Outside these regions, the day-time condensation parameterization remains unmodified. Figure 7 shows that this threshold effectively separates the regions where bio-fuel and open burning dominate over fossil fuel burning. This simulation is likely to over-estimate the ageing time-scale since the process of condensation of semi-volatile organic gases, as well as sulphuric acid condensation, is neglected. The BC burdens and deposition rates from these sensitivity 
Table 3. Global and annual mean BC burdens, lifetimes, and deposition rates from the sensitivity studies related to the condensation and coagulation parameterization.

\begin{tabular}{lllll}
\hline & COND-COAG & MODR-COND-COAG & MODB-COND-COAG & COAG \\
\hline Emission (Tg C/yr) & 8.01 & 8.01 & 8.01 & 8.01 \\
Burden (Tg C) & 0.109 & 0.113 & 0.140 & 0.171 \\
Lifetime (days) & 5.0 & 5.1 & 6.4 & 7.8 \\
Wet dep (Tg C/yr) & 5.99 & 5.96 & 5.96 & 5.99 \\
Dry dep (Tg C/yr) & 2.02 & 2.05 & 2.05 & 2.02 \\
\hline
\end{tabular}

Table 4. Global and annual mean BC burdens, lifetimes, and deposition rates from the sensitivity studies related to the oxidation parameterization.

\begin{tabular}{lccc}
\hline & OXID $(0.001)$ & OXID $(0.01)$ & OXID $(0.1)$ \\
\hline Emission (Tg C/yr) & 8.01 & 8.01 & 8.01 \\
Burden (Tg C) & 0.483 & 0.209 & 0.106 \\
Lifetime (days) & 22.0 & 9.5 & 4.8 \\
Wet dep (Tg C/yr) & 5.75 & 6.00 & 6.00 \\
Dry dep (Tg C/yr) & 2.24 & 2.01 & 2.01 \\
\hline
\end{tabular}

tests are shown in Table 3. The best prediction of the BC burden for the open burning dominated regions may then lie somewhere between the result the MODB-COND-COAG and COND-COAG simulations.

The global and annual mean BC burdens from the MODRCOND-COAG and MODB-COND-COAG give the upper bounds on the $\mathrm{BC}$ burden estimates as compared to the COND-COAG simulation. Recent work (Abel et al., 2003) suggests that $\mathrm{BC}$ does age rapidly in the open burning zones, and so there is reason to believe that the COND-COAG simulation may, in fact, be closer to reality for these regions, although not technically correct. Additionally, one may argue that in the remote regions, there is less sulphuric acid, but there is also less BC, and so the ageing time-scale developed for the more polluted regimes may still be appropriate. This further supports the idea that the COND-COAG simulation maybe closer to reality than either of these two sensitivity tests. An additional sensitivity test was conducted to show the relative importance of the processes of coagulation on a global scale. This simulation (COAG) assumed that coagulation was the only process contributing to $\mathrm{BC}$ ageing over the entire diurnal cycle. The $\mathrm{BC}$ burdens and deposition rates from this sensitivity test are also shown in Table 3. Both condensation and coagulation are shown to contribute significantly to $\mathrm{BC}$ ageing.
Table 5. Global and annual mean BC burdens, lifetimes, and deposition rates from the sensitivity studies related to emissions. Emissions are scaled by factors shown in table. All results shown are for the FIX-LIFE simulation.

\begin{tabular}{lccc}
\hline & $0.5 \times$ EMISS & $1.0 \times$ EMISS & $2.0 \times$ EMISS \\
\hline Emission (Tg C/yr) & 4.00 & 8.01 & 16.02 \\
Burden (Tg C) & 0.071 & 0.145 & 0.317 \\
Lifetime (days) & 6.5 & 6.6 & 7.2 \\
Wet dep (Tg C/yr) & 2.98 & 6.09 & 12.29 \\
Dry dep (Tg C/yr) & 1.02 & 1.92 & 3.73 \\
\hline
\end{tabular}

\subsection{Sensitivity to oxidation parameterization}

The OXID simulation gave the slowest ageing but this is dependent on the scaling factor $(0.01)$ chosen in the parameterization to account for the physical shielding effects. To investigate the impact of this factor, two other values are chosen, 0.1 and 0.001 . Since this is the first study to use this factor, and its choice was rather arbitrary, a wide range of values were selected. The resulting burdens are shown in Table 4. There is a high sensitivity to this factor. The global and annual mean $\mathrm{BC}$ burden when the factor was set to 0.1 was almost the same as that from the COND-COAG simulation. Since there is no evidence available to suggest that the ageing by oxidation processes should be as significant as that by condensation and coagulation on a global scale, this simulation likely under-estimates of the ageing time-scale due to oxidation. Unfortunately, there is a high level of uncertainty associated with this factor, and it can not be used with any degree of confidence. Further laboratory studies are needed to investigate how the rate of soot oxidation relates to the rate of production of a soluble aerosol (i.e. an aerosol that could act as a cloud condensation or ice nuclei at typical atmospheric supersaturations). This will help to improve the high uncertainty related to this scaling factor, and the oxidation parameterization as a whole. 
Table 6. Simulations with different emissions inventories, and comparison with previous studies. FIX-LIFE and FIX-LIFE2 simulations use the combined Bond et al. (2004)-van der Werf et al. (2003) and Liousse et al. (1996)-Penner et al. (1993) inventories, respectively.

\begin{tabular}{lcccccc}
\hline & FIX-LIFE & FIX-LIFE2 & Lohmann et al. (1999) & Koch (2001) & Chung and Seinfeld (2002) & Stier et al. (2005) \\
\hline Emissions (Tg C/yr) & 8.01 & 13.1 & 11.7 & 12.4 & 12.0 & 7.7 \\
Burdens (Tg C) & 0.15 & 0.23 & 0.26 & 0.15 & 0.22 & 0.11 \\
Lifetimes (days) & 6.6 & 6.5 & 8.1 & 4.4 & 6.4 & 5.4 \\
\hline
\end{tabular}
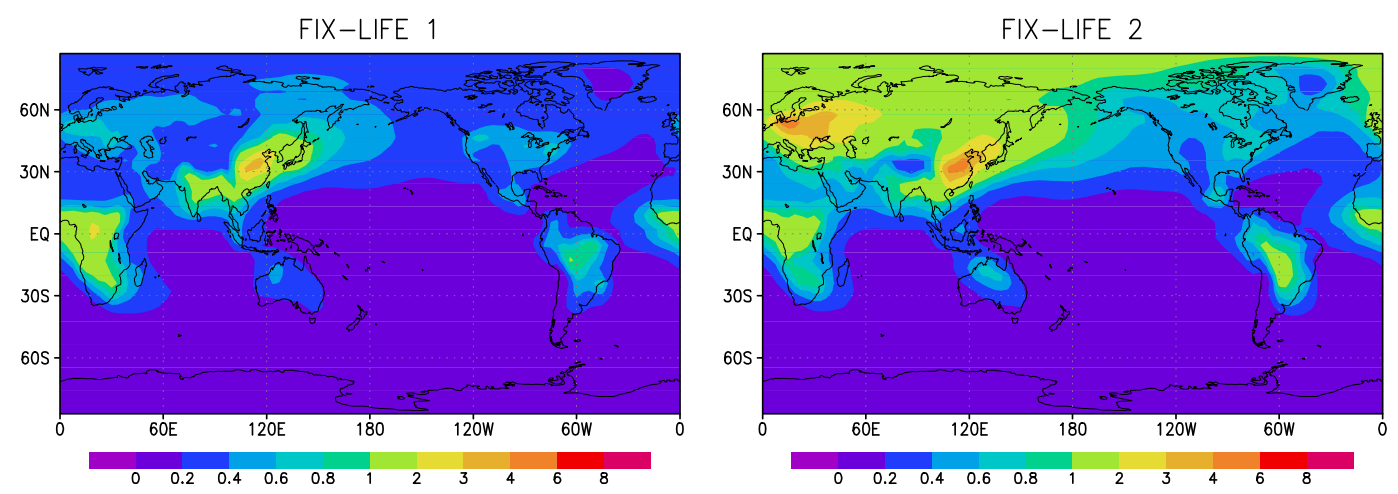

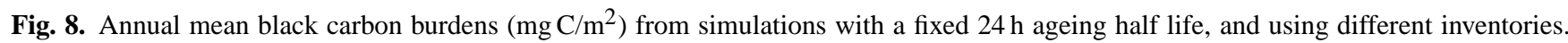
Simulation FIX-LIFE1 uses the Bond et al. (2004) and van der Werf et al. (2003) inventories, and FIX-LIFE2 uses the Penner et al. (1993) and Liousse et al. (1996) inventories.

\subsection{Sensitivity to emissions and resolution}

The $\mathrm{BC}$ emission inventory used in this study has roughly a factor of two uncertainty (Bond et al., 2004). Table 5 shows the global and annual mean results from simulations where the emissions were both increased and decreased by a factor of two. There is a high sensitivity to this factor of two uncertainty in the emissions. This highlights the importance of ongoing work to prepare accurate emission inventories. Indeed, in terms of the modelled BC burden, there is a greater sensitivity to the factor of two uncertainty in the emissions inventory than there is to any of the ageing parameterizations with the exception of the oxidation based parameterization. One of the few studies published to date using this same emission inventory in an AGCM was the study was by Stier et al. (2005). This study used an explicit representation of the processes of condensation and coagulation that was more computationally demanding than the parameterizations presented here. These authors found a annual and global mean $\mathrm{BC}$ burden of $0.11 \mathrm{Tg} \mathrm{C}$. This is the same as the result of the COND-COAG simulation of this study.

Another frequently used emission inventory combines the open burning emissions from Liousse et al. (1996) and the fossil fuel burning emissions from Penner et al. (1993). This inventory is representative of the mid 1980's, whereas the inventory used elsewhere in this study is representative of the latter 1990's. The FIX-LIFE simulation has been repeated with this inventory and is shown as FIX-LIFE2. The burdens, lifetimes and deposition rates are shown in Table 6. One must be cautious not to conclude that global BC emissions have decreased as significantly as shown in the Table 6. Observations from the IMPROVE (Interagency Monitoring of Protected Visual Environments) dataset do show a downward trend in BC surface concentrations, but the significant difference between these emission inventories may largely reflect uncertainties in the inventories themselves. A comparison of the geographic distribution of the $\mathrm{BC}$ burdens is shown in Fig. 8. Over much of Europe and Asia, BC burdens are higher by a factor of between 2 and 3 in the FIX-LIFE2 simulation. The FIX-LIFE simulation does have higher BC burdens in the southern portion of Africa. The inventory used in FIX-LIFE had higher open burning emissions in this region. Also shown in Table 6 is a comparison with other studies. These results show that the global BC burden has a high sensitivity to the inventory used. Indeed, the burdens are roughly proportional to the emissions in the global and annual mean. Thus, a factor of two uncertainty in the emissions is expected to translate into a factor of two uncertainty in the predicted BC burdens.

Another issue to consider is the impact of model resolution on the $\mathrm{BC}$ burdens, concentrations, and lifetimes. To investigate this further, the model was also run at a T63 resolution. The global and annual BC burden was found to decrease by only about 3 percent when applying the $\mathrm{BC}$ emissions at 

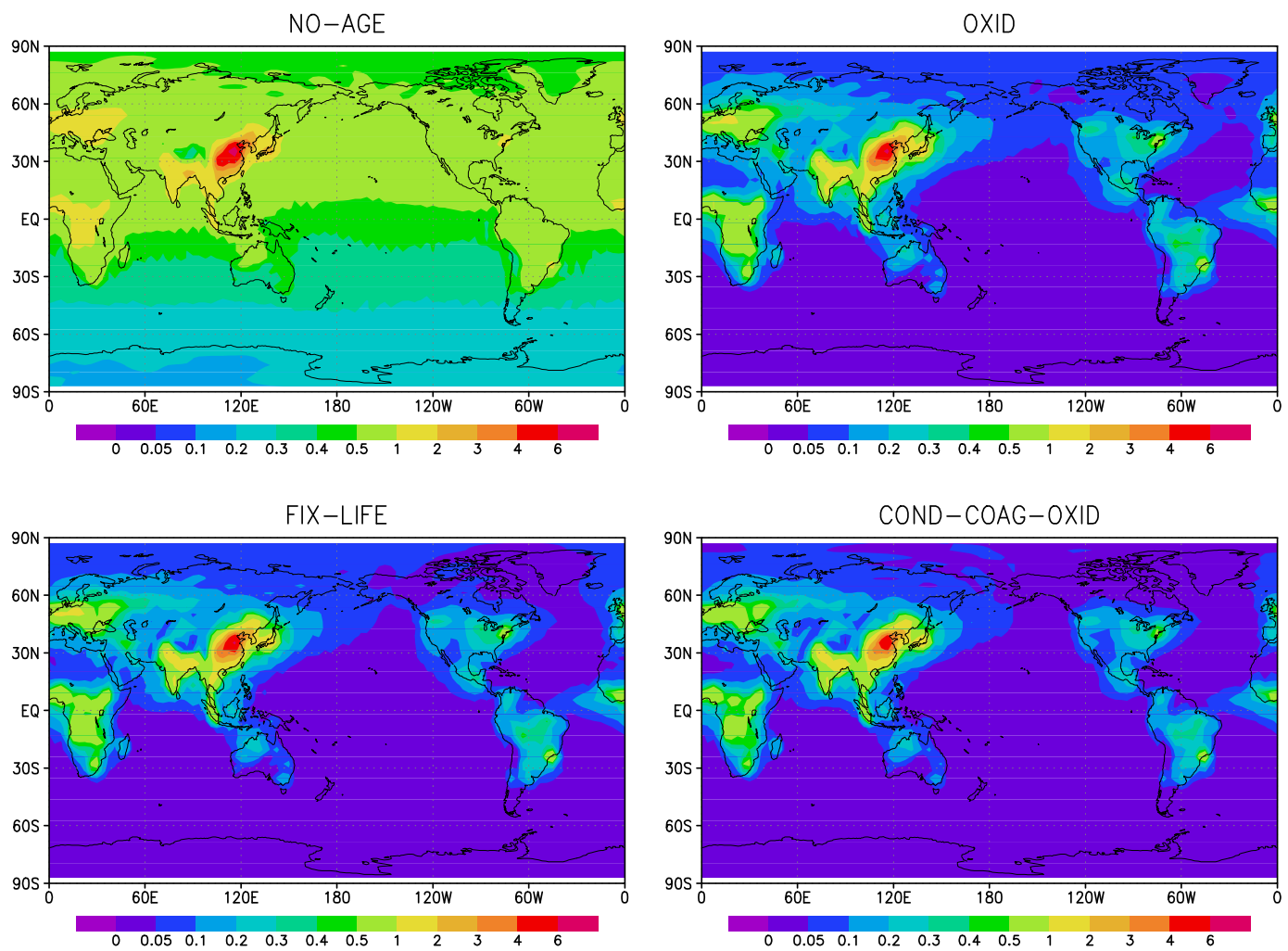

Fig. 9. Annual mean surface layer BC concentrations $\left(\mu \mathrm{g} / \mathrm{m}^{3}\right)$ from four of the simulations.

this resolution as compared to the T47 resolution used elsewhere in this study. The global and annual mean BC lifetime was found to be 4.8 days when applying the COND-COAGOXID ageing parameterization at this higher resolution, as opposed to 4.9 days at T47 resolution. This gives confidence that the parameterization of the $\mathrm{BC}$ ageing is robust since very similar results are found at higher resolution model runs.

\section{Comparison with surface layer observations}

There is a limited availability of observations of monthly mean BC surface layer concentrations over the complete annual cycle. Figure 9 shows the modelled surface layer $\mathrm{BC}$ concentrations for the simulations NO-AGE, FIX-LIFE, OXID, and COND-COAG-OXID. Figure 10 shows a comparison of observations with modelled results for four continentally influenced sites. Figures 11 and 12 are similar but for seven remote sites. To summarize on a regional scale, the IMPROVE data was domain averaged over all sites participating in the IMPROVE project, and reporting BC concentrations between June 1998 and June 2002, to obtain the monthly means. AGCM results are also domain averaged over the corresponding model grid boxes. Details regarding the other datasets can be found in the respective papers quoted with each figure. Note that all plots in this section show concentration on a logarithmic scale.
For the continentally influenced sites, there is a tendency for the model to under-estimate the observations. This is particularly evident for the sites in Japan and Austria. Even the NO-AGE simulation is less than these observations. This is with the exception of the Austrian FIX-LIFE2 simulation, which uses the older emissions inventory that appears to perform better. In part, the under-estimation problem may occur since these observations are taken closer to an urban plume, and are not representative of the mean of the GCM grid box. Otherwise, the NO-AGE simulation over-estimates the surface concentrations. This points to the importance of the ageing parameterization in AGCMs. For the remote sites, the over-estimation is greater, one or two orders of magnitude. This is expected given the longer distance from the emission sources, and the greater time frame that ageing processes occurred.

The model results compare best with the observations for the IMPROVE domain, and the Alert site. Both datasets are means over a 3-4 year period and appropriate to the year of the emissions inventory. This improves the comparison. Additionally, the IMPROVE comparison has the benefit of a wider spatial coverage of observations, which will be more representative of the GCM grid box means. Particularly near the poles, natural variability can cause large differences between years, and thus a dataset averaged over several years is desirable. Also, there is likely less inter-annual variability 

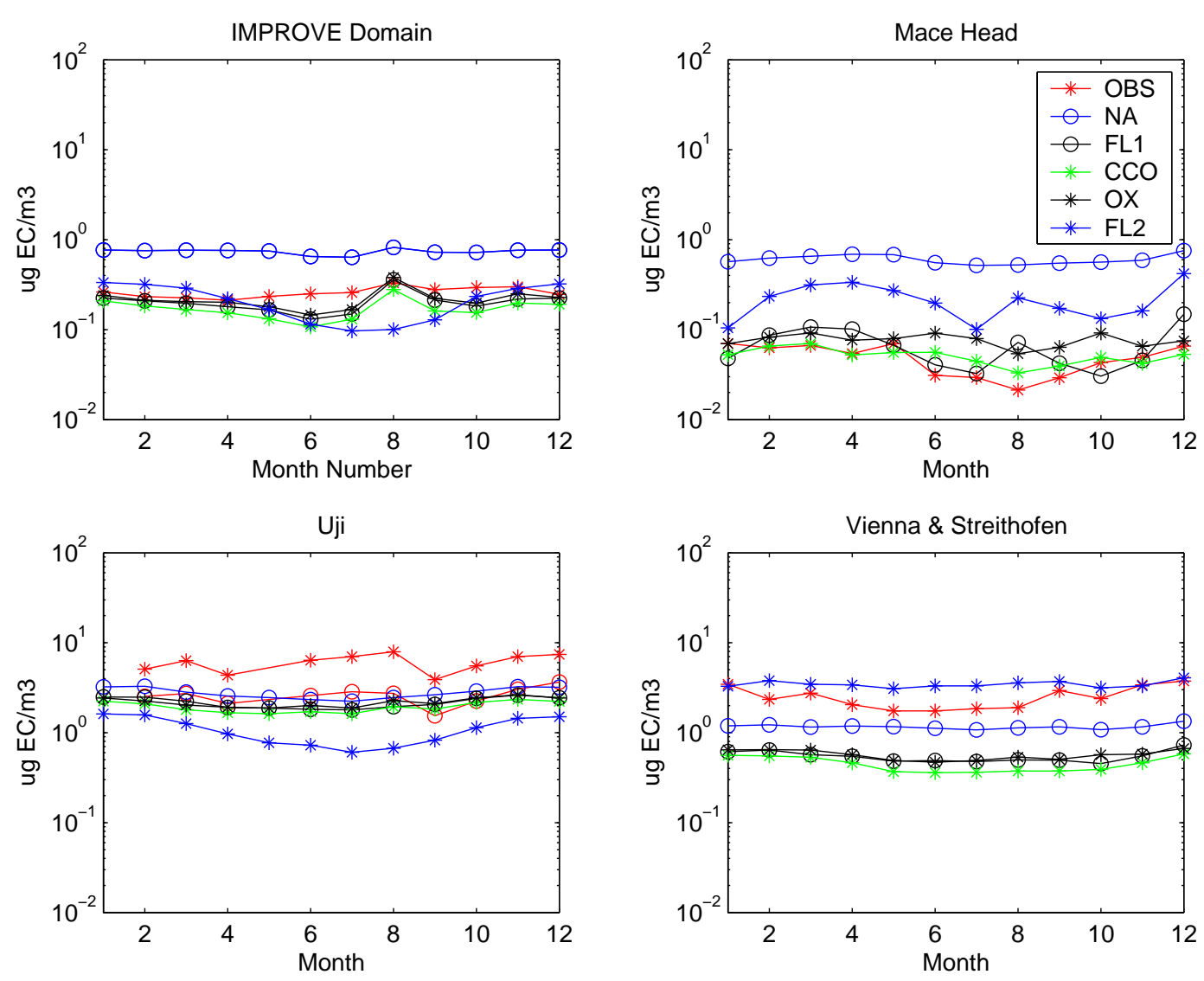

Fig. 10. Continentally influenced monthly mean surface layer BC concentrations from U.S.A. IMPROVE domain average from 19982002, Mace Head, Ireland (Cooke et al., 1997), Uji, Japan (Höller et al., 2002), and Vienna-Streithofen, Austria (Puxbaum et al., 2004). Observations are in red. For Uji, open circles are data prior to correction for small particle mass. Simulations shown are NO-AGE (NA), FIX-LIFE (FL1), COND-COAG-OXID (CCO), OXID (OX), FIX-LIFE2 (FL2). Legend shown applies to all plots.

in the North American fossil fuel dominated emissions compared to the Southern Hemisphere emissions, which are dominated by open burning. Additionally, several of the observations are from the early and mid-1990s, such as for the Mace Head site, and this affects the comparison.

In many cases, the COND-COAG-OXID simulation gives $\mathrm{BC}$ concentrations slightly lower than the FIX-LIFE simulation, i.e. the ageing half life is predicted to be less than $24 \mathrm{~h}$. The opposite is seen at the Antarctica site. Slower ageing is expected there since this region of the southern hemisphere has lower aerosol number concentrations, which slows the ageing process. The COND-COAG-OXID has the advantage over the FIX-LIFE simulation in that it captures these regionally varying effects.

A statistical comparison can be made between the model simulations in order to help draw conclusions regarding the performance of these parameterizations. The annual mean model to observation ratio, and the correlation coefficient between modelled and observed surface layer monthly mean $\mathrm{BC}$ concentrations are shown in Table 7. The COND-COAG simulation is shown to perform best both in terms of captur- ing the seasonal cycle and in predicting the magnitude of the BC concentrations. While the improvement over the FIXLIFE simulation is not as large as one might like to see, this crude physically based parameterization does show a preliminary improvement. In future work, this parameterization may be refined by linking the ageing time-scale more precisely to the rate of sulphate production and uptake of soluble mass on the BC aerosol. This will be possible as further laboratory and field studies are conducted to better investigate these physical and chemical processes. The approach shown in Kanakidou et al. (2005) that links the ageing time-scale to the rate of sulphate production, relative size of the aerosols, mass of insoluble aerosol, and number concentration is the accumulation mode shows promise. However, there is need to better validate the parameters used in the equations, and extend the approach to include the heterogenous and aqueous phase reactions that may be of importance (i.e. chemical ageing).

Table 7 shows that the simulation OXID gave the greatest over-estimation of the concentrations in comparison to observations. This result is highly dependent on the tunable factor 

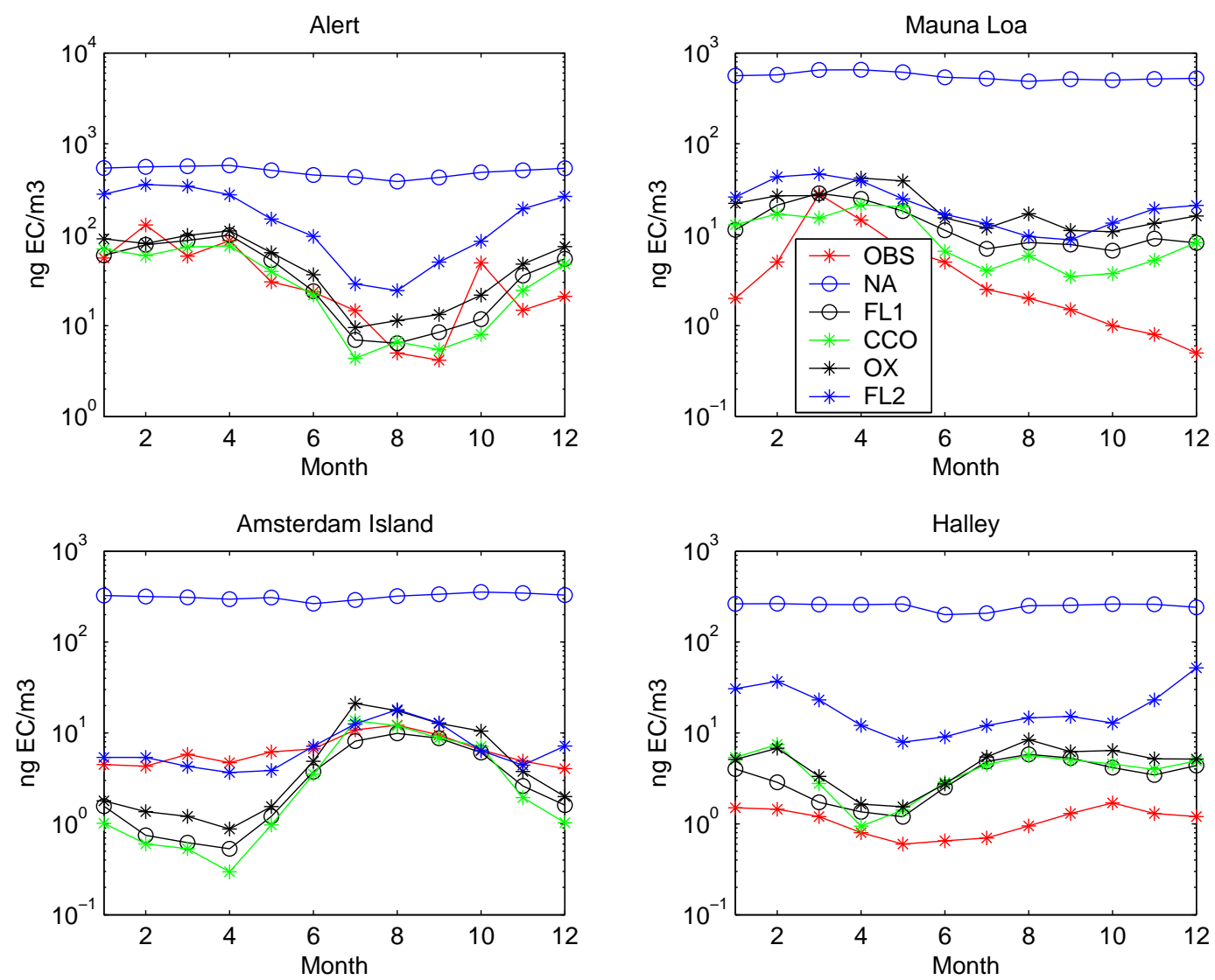

Fig. 11. Remote site monthly mean surface layer BC concentrations at Alert averaged over period 1999-2001 (Sharma et al., 2004), Mauna Loa (Bodhaine, 1995), Amsterdam Island (Wolff and Cachier, 1998), and Halley (Wolff and Cachier, 1998). Observations are in red. Simulations shown are NO-AGE (NA), FIX-LIFE (FL1), COND-COAG-OXID (CCO), OXID (OX), FIX-LIFE2 (FL2). Legend shown applies to all plots.

of 0.01 that was used. The tuning factor can be increased to give a model to observation ratio quite close to unity. However, this was not done since there is no evidence available yet to suggest that ageing due to oxidation should be a more dominant process on a global scale than coagulation and condensation. Further, a greater global coverage of observations is needed before there can be any reasonable level of certainty about the value of this tuning factor used in the OXID and COND-COAG-OXID simulations. Thus, there remains a very high level of uncertainty pertaining to the oxidation parameterization.

In considering the collective of the 11 observation sites in the annual mean, the model does estimate the $\mathrm{BC}$ concentrations within a factor of two of the observations. However, in a more specific regional, and month to month comparison some of the simulations do predict closer to within a factor of ten. The comparison is generally poorer at the remote sites. This reflects both the uncertainty in the transport processes, combined with the longer time that errors in the ageing and removal processes have had to compound. Additionally, at the majority of the sites, the FIX-LIFE2 simulation, which
Table 7. Ratio of monthly mean modelled to observed surface layer BC concentrations, and correlation between monthly mean observed and predicted concentrations. Results shown are the mean over the 11 surface comparison sites for the simulations NO-AGE, FIX-LIFE, OXID, COND-COAG, and COND-COAG-OXID.

\begin{tabular}{lcc}
\hline & Ratio & Correlation \\
\hline NO-AGE & 77.6 & 0.50 \\
FIX-LIFE & 1.96 & 0.80 \\
COND-COAG & 1.73 & 0.82 \\
OXID & 2.39 & 0.82 \\
COND-COAG-OXID & 1.75 & 0.82 \\
\hline
\end{tabular}

uses an older emissions inventory, is often the farthest from the observations.

Open burning is known to contribute significantly to global $\mathrm{BC}$ emissions and burdens. However, there is a scarcity of observations of $\mathrm{BC}$ concentrations from the open burning regions of Africa and South America over the complete annual 

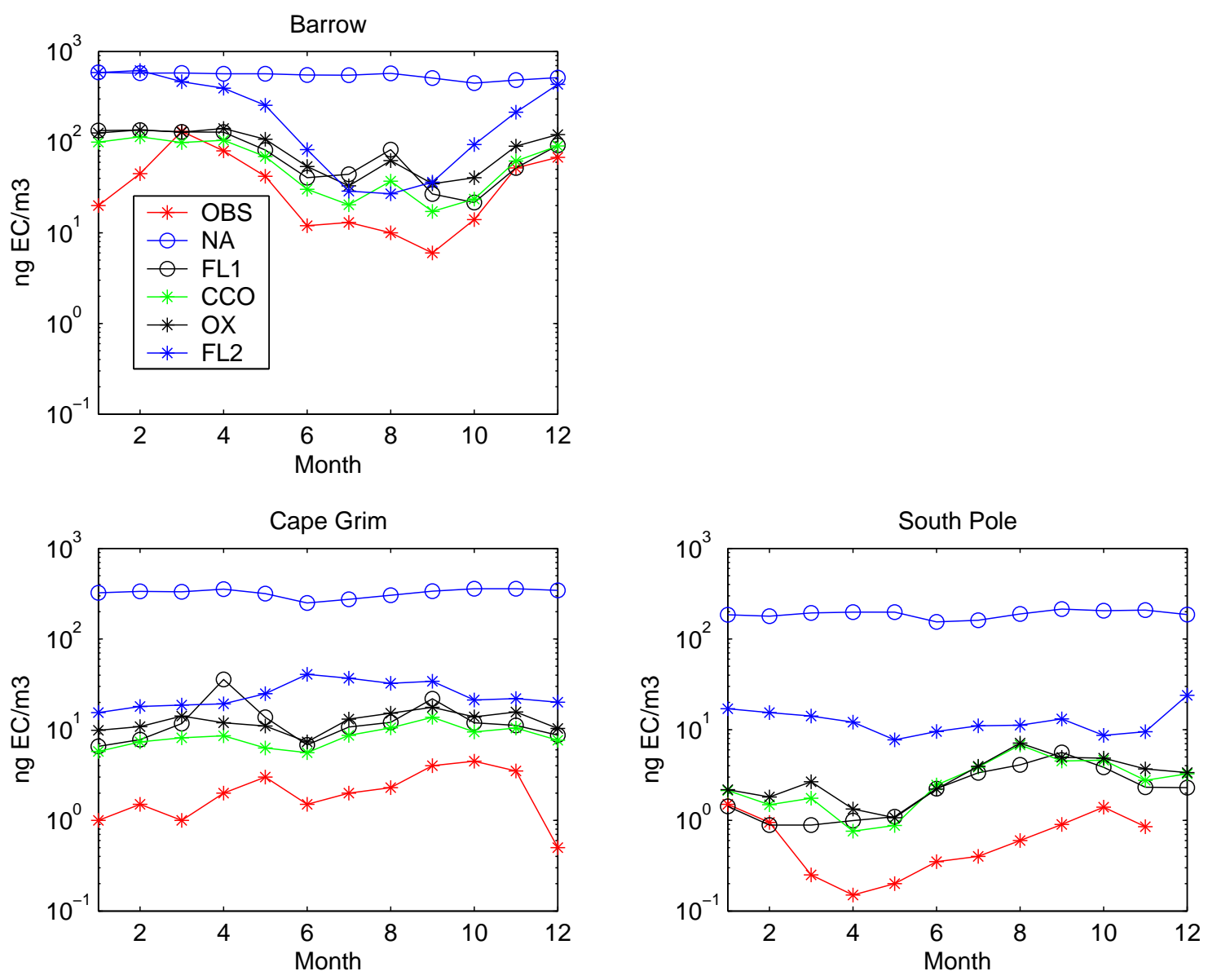

Fig. 12. Remote site monthly mean surface layer BC concentrations at Barrow (Bodhaine, 1995), Cape Grim (Heintzenberg and Bigg, 1990) and Amundsen-Scott, South Pole (Bodhaine, 1995). Observations are in red. Simulations shown are NO-AGE (NA), FIX-LIFE (FL1), COND-COAG-OXID (CCO), OXID (OX), FIX-LIFE2 (FL2). Legend shown applies to all plots.

Table 8. Comparison of surface layer BC concentrations $\left(\mathrm{ng} / \mathrm{m}^{3}\right)$ from regions dominated by open burning regions with three model simulations FIX-LIFE (FL), COND-COAG-OXID (CCO), and FIX-LIFE2 (FL2). The FL and CCO simulations use the combined Bond et al. (2004) and van der Werf et al. (2003) emission inventories. The FL2 simulation uses the combined Liousse et al. (1996) and Penner et al. (1993) emission inventories.

\begin{tabular}{lllllllll}
\hline & Lon & Lat & Date & Observed & FL & CCO & FL2 & Reference \\
\hline Central Africa & $17-19 \mathrm{E}$ & $2-12 \mathrm{~N}$ & Nov/Dec & 3363 & 1047.2 & 923.8 & 1586.5 & Ruellan et al. (1999) \\
Ivory Coast & $5.1 \mathrm{~W}$ & $6.2 \mathrm{~N}$ & Annual & 1300 & 541.5 & 475.6 & 2241.2 & Wolff and Cachier (1998) \\
South America & $79.7 \mathrm{~W}$ & $2.25 \mathrm{~S}$ & June & 520 & 122.2 & 106.1 & 813.7 & Andreae et al. (1984) \\
\hline
\end{tabular}

cycle. Open burning does have a strong seasonal cycle as is shown in Fig. 13. Given the importance of these regions, a preliminary comparison was made with available observations. This comparison is shown in Table 8 . The model tends to under-estimate the concentrations for the majority of the comparisons. The FIX-LIFE2 simulation gives concentrations within a factor of 2 of the observations. The FIX-
LIFE and COND-COAG-OXID simulations give concentrations that are within a factor of 3 to 4 of the observations, with a more consistent tendency to under-estimate the observations than the FIX-LIFE2 simulation. Given the significance of open burning emissions, and the high spatial and temporal variation of these emissions, as shown in Fig. 13, new satellite retrievals should be of great help in validating 

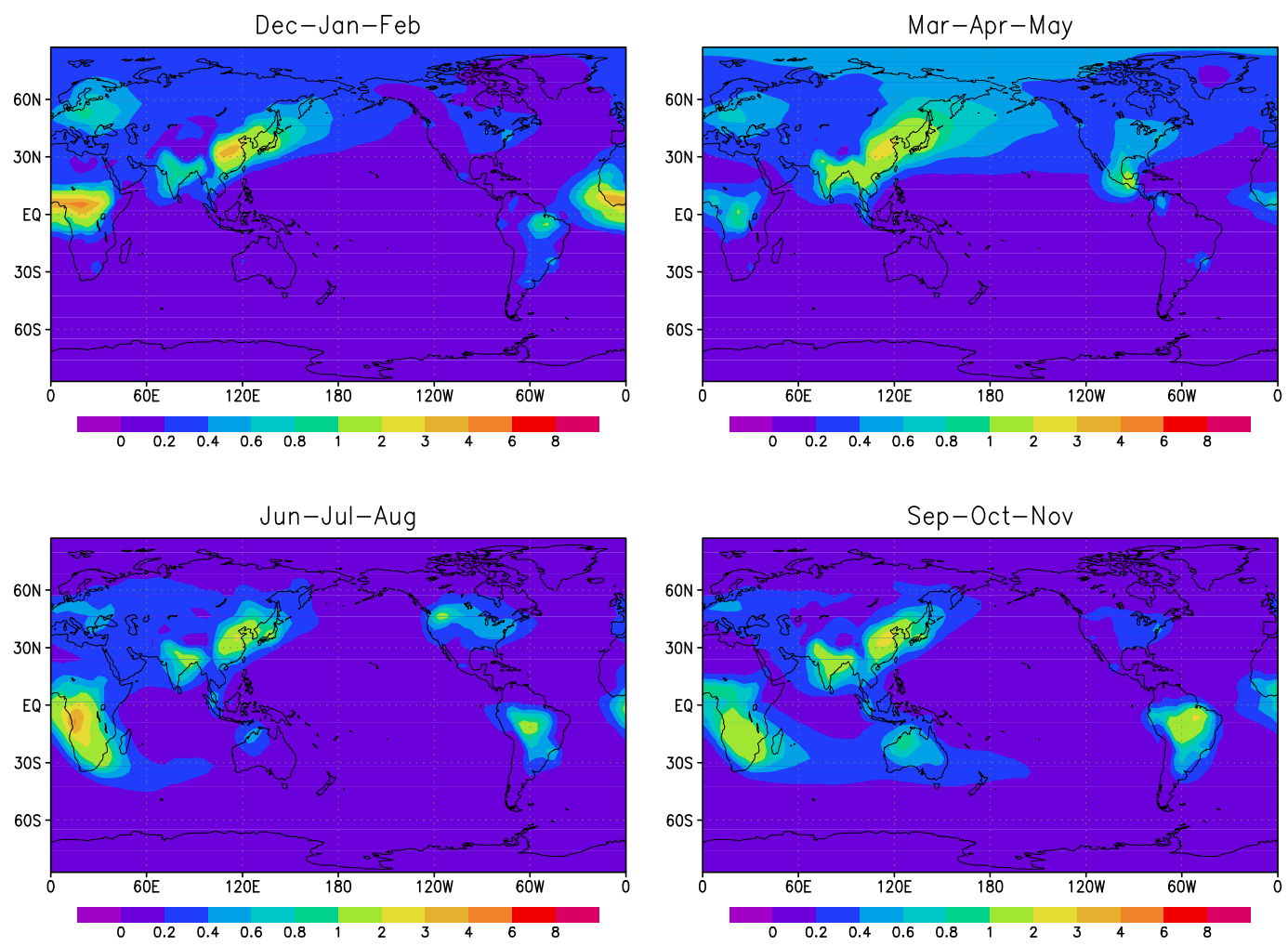

Fig. 13. Seasonal cycle of $\mathrm{BC}$ burdens $\left(\mathrm{mg} \mathrm{C} / \mathrm{m}^{2}\right)$ from the COND-COAG-OXID simulation.

the predicted $\mathrm{BC}$ concentrations in the coming years.

In summary, one must exercise caution in drawing conclusions related to comparisons of AGCM surface layer concentrations with observations. Factors to consider include, 1) how representative are the observations, taken at one site, of the grid box mean, 2) is there significant variability in the concentrations on an inter-annual basis that sensitizes the comparison to the year of the emissions scenario used by the model, and 3) may the uncertainty in the emission scenario used vary considerably on a regional basis. The best match of comparison conditions are likely for the IMPROVE domain and at Alert. Results here demonstrate that the ageing parameterizations work well as opposed to the assumption of no ageing.

\section{Conclusions}

Four separate parameterizations of the $\mathrm{BC}$ ageing process, suitable for use in a AGCM, have been examined in this study. The assumption of no ageing was shown to be clearly unphysical, and significantly over-estimated the observed BC surface layer concentrations. This occurred since a high percentage of the total $\mathrm{BC}$ mass remained in the insoluble fraction. Thus, there was less efficient removal by wet deposition, which was shown to account for roughly $75 \%$ of the total deposition. A parameterization developed by
Riemer et al. (2004a) to represent BC ageing by condensation and coagulation processes was tested for the first time in an AGCM. This parameterization represented the BC ageing process reasonably on a global basis, despite being designed in a domain dominated by fossil fuel burning. Results from this simulation suggested that the global and annual mean half-life for the conversion of insoluble BC to soluble BC is less than the $24 \mathrm{~h}$. For the first time, a parameterization that included the processes of condensation, coagulation, and oxidation was developed and used in an AGCM. The contribution of oxidation to the $\mathrm{BC}$ ageing process was modelled to be small. However, there remains a very high level of uncertainty associated with the oxidative parameterization. The contribution of oxidation to $\mathrm{BC}$ ageing on a global is simply not conclusively known as yet. On a global scale, condensation and coagulation contribute significantly to $\mathrm{BC}$ ageing. The assumption of an exponential decay of insoluble $\mathrm{BC}$ to the soluble/mixed state with a fixed $24 \mathrm{~h}$ half life was also shown to represent BC burdens reasonably. However, this approach has the disadvantage in that it is not responsive to varying regional conditions. $\mathrm{BC}$ burdens were $2.15,0.15$, $0.11,0.21$, and $0.11 \mathrm{TgC}$, for the simulations, assuming 1) no ageing, 2) a fixed half life of $24 \mathrm{~h}, 3$ ) ageing by condensation and coagulation, 4) ageing by oxidation with ozone, and 5) ageing by condensation, coagulation, and oxidation combined, respectively. For the same simulations respectively, 
BC lifetimes were 98.1, 6.6, 5.0, 9.5, and 4.9 days.

The sensitivity of the modelled BC burdens and concentrations to the factor of two uncertainty in the emissions inventories was shown to be greater than the sensitivity to the parameterization used to represent $\mathrm{BC}$ ageing, except for the oxidation based parameterization. This highlights the importance of work to reduce the uncertainties in $\mathrm{BC}$ emission inventories, and to better understand the processes of chemical ageing. Future changes in atmospheric composition will lead to changes in the $\mathrm{BC}$ ageing time-scale. A physically and chemically based $\mathrm{BC}$ ageing treatment will allow the AGCM to better respond to these changes in oxidants and pollutants, as opposed to the use of a fixed e-folding time.

In terms of future research directions, more spatially extensive observations of $\mathrm{BC}$ burdens, seasonal fluctuations, and deposition rates are needed, both to validate modelling efforts, and to more clearly define the atmospheric abundance of this important aerosol. Further experiments are needed to better understand the mechanisms by which the processes of oxidation, coagulation, and condensation (not only of inorganic acids but also of semi-volatile organic gases) interact and convert insoluble BC particles into particles can act as cloud condensation or ice nuclei. Ultimately, this will help to resolve one of the major uncertainties in climate modelling and research, the role of cloud-aerosol interactions.

Acknowledgements. The authors wish to acknowledge the Meteorological Service of Canada that generously provided the valuable computer time required by this project. The authors thank Nicole Riemer for helpful discussions. This work was supported by the National Science and Engineering Research Council of Canada, and the Canadian Foundation for Climate and Atmospheric Science collaborative research grants.

Edited by: U. Pöschl

\section{References}

Abel, S. J., Haywood, J. M., Highwood, E. J., Li, J., and Buseck, P. R.: Evolution of biomass burning aerosol properties from an agricultural fire in southern Africa, Geophys. Res. Lett., 30, doi:10.1029/2003GL017342, 2003.

Binkowski, F. S. and Shankar, U.: The regional particulate matter model, 1. Model description and preliminary results, J. Geophys. Res., 100, 26 191-26 209, 1995.

Bodhaine, B. A.: Aerosol absorption measurements at Barrow, Mauna Loa and the South-Pole, J. Geophys. Res., 100, 89678975, 1995.

Boer, G. J.: Analyzed and forecast large-scale tropical divergent flow, Mon. Wea. Rev., 123, 3539-3553, 1995.

Bond, T. C., Streets, D. G., Yarber, K. F., Nelson, S. M., Woo, J.H., and Klimont, Z.: A technology-based global inventory of black and organic carbon emissions from combustion, J. Geophys. Res., 109, D14 203, doi:10.1029/2003JDO03 697, 2004.

Chung, S. H. and Seinfeld, J. H.: Global distribution and climate forcing of carbonaceous aerosols, J. Geophys. Res., 107, D19 407, doi:10.1029/2001JD001 397, 2002.
Chylek, P., Kou, L., Johnson, B., Boudala, F., and G.Lesins: Black carbon concentrations in precipitation and near surface air in and near Halifax, Nova Scotia, Atmos. Environ., 33, 2269-2277, 1999.

Cooke, W. F., Jennings, S. G., and Spain, T. G.: Black carbon measurements at Mace Head, 1989-1996, J. Geophys. Res., 102, 25 339-25 346, 1997.

Cooke, W. F., Liousse, C., Cachier, H., and Feichter, J.: Construction of a $1 \times 1$ fossil fuel emission data set for carbonaceous aerosol and implementation and radiative impact in the ECHAM4 model, J. Geophys. Res., 104, 22 137-22 162, 1999.

Cooke, W. F., Ramaswamy, V., and Kasibhatla, P.: A general circulation model study of the global carbonaceous aerosol distribution, J. Geophys. Res., 107, doi:10.1029/2001JD001 274, 2002.

Decesari, S., Facchini, M. C., Matta, E., Mircea, M., Fuzzi, S., Chughtai, A. R., and Smith, D. M.: Water soluble organic compounds formed by oxidation of soot, Atmos. Environ., 36, 18271832, 2002.

Feichter, J., Kjellström, E., Rodhe, H., Dentener, F., Lelieveld, J., and Roelofs, G.-J.: Simulation of the tropospheric sulfur cycle in a global climate model, Atmos. Environ., 30, 1693-1707, 1996.

Haywood, J. and Boucher, O.: Estimates of the direct and indirect radiative forcing due to tropospheric aerosols: A review, J. Geophys. Res., 38, doi:10.1029/1999RG000 078, 2000.

Heintzenberg, J. and Bigg, E. K.: Tropospheric transport of trace substances in the Southern Hemisphere, Tellus, 42B, 355-363, 1990.

Hess, M., Koepke, P., and Schult, I.: Optical properties of aerosols and clouds: The software package OPAC, Bull. Am. Meterol. Soc., 79, 831-844, 1998.

Hitzenberger, R., Berner, A., Giebl, H., Drobesch, K., KasperGiebl, A., Loeflund, M., Urban, H., and Puxbaum, H.: Black carbon (BC) in alpine aerosols and cloud water - concentrations and scavenging efficiencies, Atmos. Environ., 35, 5135-5141, 2001.

Hobbs, P. V., Sinha, P., Yokelson, R. J., Christian, T. J., Blake, D. R., Gao, S., Kirchstetter, T. W., Novakov, T., and Pilewskie, P.: Evolution of gases and particles from a savanna fire in South Africa, J. Geophys. Res., 108, doi:10.1029/2003GL017 342, 2003.

Höller, R., Tohno, S., Kasahara, M., and Hitzenberger, R.: Longterm characterization of carbonaceous aerosol in Uji, Japan, Atmos. Environ., 36, 1267-1275, 2002.

Kanakidou, M., Seinfeld, J. H., Pandis, S. N., Barnes, I., Dentener, F. J., Facchini, M. C., Dingenen, R. V., Ervens, B., Nenes, A., Nielsen, C. J., Swietlicki, E., Putaud, J. P., Balkanski, Y., Fuzzi, S., Horth, J., Moortgat, G. K., Winterhalter, R., Myhre, C. E. L., Tsigaridis, K., Vignato, E., Stephanou, E. G., and Wilson, J.: Organic aerosol and global climate modelling: A review, Atmos. Chem. Phys., 5, 1053-1123, 2005,

SRef-ID: 1680-7324/acp/2005-5-1053.

Koch, D.: Transport and direct radiative forcing of carbonaceous and sulfate aerosols in the GISS GCM, J. Geophys. Res., 106, 20311-20332, 2001.

Liousse, C., Penner, J. E., Chung, C., Walton, J. J., Eddleman, H., and Cachier, H.: A global three-dimensional model study of carbonaceous aerosols, J. Geophys. Res., 101, 19411-19432, 1996.

Lohmann, U.: A glaciation indirect effect caused by soot aerosols, Geophys. Res. Lett., 29, doi: 10.1029/2001GL014 357, 2002. 
Lohmann, U. and Feichter, J.: Impact of sulfate aerosols on albedo and lifetime of clouds: A sensitivity study with the ECHAM4 GCM, J. Geophys. Res, 102, 13 685-13 700, 1997.

Lohmann, U. and Feichter, J.: Global indirect aerosol effects: a review, Atmos. Chem. Phys., 5, 715-737, 2005,

SRef-ID: 1680-7324/acp/2005-5-715.

Lohmann, U., Feichter, J., Chuang, C. C., and Penner, J. E.: Prediction of the number of cloud droplets in the ECHAM GCM, J. Geophys. Res., 104, 9169-9198, 1999.

Lord, S. J.: Interaction of a cumulus cloud ensemble with largescale environment, part III; Semi-prognostic test of the ArakawaSchubert cumulus parameterization, J. Atmos. Sci., 39, 88-103, 1982.

Merryfield, W. J. and Holloway, G.: Application of an accurate advection algorithm to sea-ice modelling, Ocean Modelling, 5, 115, 2003.

Peng, Y., Lohmann, U., Leaitch, R., Banic, C., and Couture, M.: The cloud albedo-cloud droplet effective radius relationship for clean and polluted clouds from RACE and FIRE.ACE, J. Geophys. Res., 107, doi:10.1029/2000JD000 281, 2002.

Penner, J. E., Eddleman, H., and Novakov, T.: Towards the development of a global inventory for black carbon emissions, Atmos. Environ., 27A, 1277-1295, 1993.

Pöschl, U., Letzel, T., Schauer, C., and Niessner, R.: Interaction of ozone and water vapor with spark discharge soot aerosol particles coated with benzo[a]pyrene: $\mathrm{O}_{3}$ and $\mathrm{H}_{2} \mathrm{O}$ adsorption, benzo[a]pyrene degradation, and atmospheric implications, J. Phys. Chem., 105, 4029-4041, 2001.

Puxbaum, H., Gomiscek, B., Kalina, M., Salam, A., Stopper, S., Preining, O., and Hauck, H.: A dual study $\mathrm{PM}_{2.5}$ and $\mathrm{PM}_{10}$ aerosol chemistry in the larger region of Vienna, Austria, Atmos. Environ., 38, 3949-3958, 2004.

Reader, M. C., Fung, I., and McFarlane, N.: The mineral dust aerosol cycle during the Last Glacial Maximum, J. Geophys. Res., 104 D8, 9381-9398, 1999.

Riemer, N., Vogel, H., and Vogel, B.: A parameterisation of the soot aging for global climate models, Atmos. Chem. Phys. Discuss., 4, 2089-2115, 2004a.
Riemer, N., Vogel, H., and Vogel, B.: Soot aging time scales in polluted regions during day and night, Atmos. Chem. Phys., 4, 1885-1893, 2004b,

SRef-ID: 1680-7324/acp/2004-4-1885.

Saathoff, H., Naumann, K.-H., Schaiter, M., Schock, W., Mohler, O., Schurath, U., Weingartner, E., Gysel, M., and Baltensperger, U.: Coating of soot and $\left(\mathrm{NH}_{4}\right)_{2} \mathrm{SO}_{4}$ particles by ozonlysis products of $\alpha$-pinene, J. Aerosol. Sci., 34, 1297-1321, 2003.

Sharma, S., Lavoue, D., Cachier, H., Barrie, L., and Gong, S. L.: Long-term trends of the black carbon concentrations in the Canadian arctic, J. Geophys. Res., 109, D15203, doi:10.1029/2003JD004 331, 2004.

Stier, P., Feichter, J., Kloster, S., Vignati, E., Wilson, J., Ganzeveld, L., Tegen, I., Werner, M., Balkanski, Y., Schult, M., and Boucher, O.: The aerosol-climate model ECHAM5-HAM, Atmos. Chem. Phys., 5, 1125-1156, 2005,

SRef-ID: 1680-7324/acp/2005-5-1125.

Tsigaridis, K. and Kanakidou, M.: Global modelling of secondary organic aerosol in the troposphere: A sensitivity analysis, Atmos. Chem. Phys., 3, 1849-1869, 2003,

SRef-ID: 1680-7324/acp/2003-3-1849.

van der Werf, G. R., Randerson, J. T., Collatz, G. J., and Giglio, L.: Carbon emissions from fires in tropical and subtropical ecosystems, Global Change Biology, 9, 547-562, 2003.

von Salzen, K., Leighton, H. G., Ariya, P. A., Barrie, L. A., Gong, S. L., Blanchet, J.-P., Spacek, L., Lohmann, U., and Kleinman, L. I.: Sensitivity of sulfate aerosol size distributions and CCN concentrations over North America to $\mathrm{SO}_{x}$ emissions and $\mathrm{H}_{2} \mathrm{O}_{2}$ concentrations, J. Geophys. Res., 105, 9741-9765, 2000.

Wolff, E. W. and Cachier, H.: Concentrations and seasonal cycle of black carbon in aerosol at a coastal Antarctic station, J. Geophys. Res., 103, 11 033-11 041, 1998.

Zuberi, B., Johnson, K. S., Aleks, G. K., Molina, L. T., and Molina, M. J.: Hydrophylic properties of aged soot, Geophys. Res. Lett., 32, L01 807, doi:10.1029/2004GL021 496, 2005. 